\title{
ORP2 interacts with phosphoinositides and controls the subcellular distribution of cholesterol
}

\section{Koponen, Annika}

2019-03

Koponen , A , Arora , A , Takahashi , K, Kentala , H, Kivelä , A M , Jääskeläinen , E , Peränen , J , Somerharju , P , Ikonen , E , Viitala , T \& Olkkonen , V M 2019 , ' ORP2 interacts with phosphoinositides and controls the subcellular distribution of cholesterol ' , Biochimie , vol. 158 , pp. 90-101 . https://doi.org/10.1016/j.biochi.2018.12.013

http://hdl.handle.net/10138/299791

https://doi.org/10.1016/j.biochi.2018.12.013

unspecified

publishedVersion

Downloaded from Helda, University of Helsinki institutional repository.

This is an electronic reprint of the original article.

This reprint may differ from the original in pagination and typographic detail.

Please cite the original version. 
Research paper

\title{
ORP2 interacts with phosphoinositides and controls the subcellular distribution of cholesterol
}

\author{
Annika Koponen ${ }^{a}$, Amita Arora ${ }^{a}$, Kohta Takahashi ${ }^{b}$, Henriikka Kentala a , \\ Annukka M. Kivelä a , Eeva Jääskeläinen ${ }^{a}$, Johan Peränen ${ }^{b}$, Pentti Somerharju ${ }^{c}$, \\ Elina Ikonen ${ }^{\mathrm{b}}$, Tapani Viitala ${ }^{\mathrm{d}}$, Vesa M. Olkkonen ${ }^{\mathrm{a}, \mathrm{b},{ }^{*}}$ \\ ${ }^{a}$ Minerva Foundation Institute for Medical Research, Biomedicum 2U, FI-00290, Helsinki, Finland \\ ${ }^{\mathrm{b}}$ Department of Anatomy, Faculty of Medicine, FI-00014, University of Helsinki, Finland \\ c Department of Biochemistry and Developmental Biology, Faculty of Medicine, FI-00014, University of Helsinki, Finland \\ ${ }^{\mathrm{d}}$ Drug Research Program, Division of Pharmaceutical Biosciences, Faculty of Pharmacy, FI-00014, University of Helsinki, Finland
}

\section{A R T I C L E I N F O}

\section{Article history:}

Received 21 March 2018

Accepted 20 December 2018

Available online 24 December 2018

\section{Keywords:}

Cholesterol

Lipid transfer

OSBP-related protein

Phosphoinositide

Surface plasmon resonance

\begin{abstract}
A B S T R A C T
ORP2 is a sterol-binding protein with documented functions in lipid and glucose metabolism, Akt signaling, steroidogenesis, cell adhesion, migration and proliferation.

Here we investigate the interactions of ORP2 with phosphoinositides (PIPs) by surface plasmon resonance (SPR), its affinity for cholesterol with a pull-down assay, and its capacity to transfer sterol in vitro. Moreover, we determine the effects of wild-type (wt) ORP2 and a mutant with attenuated PIP binding, ORP2(mHHK), on the subcellular distribution of cholesterol, and analyze the interaction of ORP2 with the related cholesterol transporter ORP1L.

ORP2 showed specific affinity for $\mathrm{PI}(4,5) \mathrm{P}_{2}, \mathrm{PI}(3,4,5) \mathrm{P}_{3}$ and $\mathrm{PI}(4) \mathrm{P}$, with suggestive $\mathrm{K}_{\mathrm{d}}$ values in the $\mu \mathrm{M}$ range. Also binding of cholesterol by ORP2 was detectable, but a $\mathrm{K}_{\mathrm{d}}$ could not be determined. Wt ORP2 was in HeLa cells mainly detected in the cytosol, ER, late endosomes, and occasionally on lipid droplets (LDs), while ORP2(mHHK) displayed an enhanced LD localization. Overexpression of wt ORP2 shifted the D4H cholesterol probe away from endosomes, while ORP2(mHHK) caused endosomal accumulation of the probe. Although ORP2 failed to transfer dehydroergosterol in an in vitro assay where OSBP is active, its knock-down resulted in the accumulation of cholesterol in late endocytic compartments, as detected by both $\mathrm{D} 4 \mathrm{H}$ and filipin probes. Interestingly, ORP2 was shown to interact and partially co-localize on late endosomes with ORP1L, a cholesterol transporter/sensor at ER-late endosome junctions.

Our data demonstrates that ORP2 binds several phosphoinositides, both PI(4)P and multiply phosphorylated species. ORP2 regulates the subcellular distribution of cholesterol dependent on its PIPbinding capacity. The interaction of ORP2 with ORP1L suggests a concerted action of the two ORPs.
\end{abstract}

๑ 2018 Elsevier B.V. and Société Française de Biochimie et Biologie Moléculaire (SFBBM). All rights reserved.
Abbreviations: BiFC, bimolecular fluorescence complementation; DHE, dehydroergosterol; ER, endoplasmic reticulum; GST, glutathione-S-transferase; $\mathrm{K}_{\mathrm{d}}$, dissociation constant; LD, lipid droplet; LE, late endosome; OHC, hydroxycholesterol; ORD, OSBP-related domain; ORP, OSBP-related protein; OSBP, oxysterol-binding protein; PIP, phosphoinositide; PI(4)P, phosphatidylinositol-4phosphate; $\mathrm{PI}(4,5) \mathrm{P}_{2}$, phosphatidylinositol-4,5-bisphosphate; $\mathrm{PI}(3,4,5) \mathrm{P}_{3}$, phosphatidylinositol-3,4,5-trisphosphate; PM, plasma membrane; SPR, surface plasmon resonance; VAPA, VAMP-associated protein A.

* Corresponding author. Minerva Foundation Institute for Medical Research, Biomedicum 2U, Tukholmankatu 8, FI-00290, Helsinki, Finland

E-mail address: vesa.olkkonen@helsinki.fi (V.M. Olkkonen).

\section{Introduction}

Phosphatidylinositol phosphates (PIPs) are phosphorylated derivatives of phosphatidylinositol (PI), in which the inositol ring head group is phosphorylated at positions of 3,4 and/or 5, resulting in seven different PIPs. These lipids are of low abundance in cells and are mostly known for their signaling functions, playing central roles e.g. in membrane trafficking, cell migration and signal transduction [1]. The distribution of the distinct PIP species varies between different cellular membranes, as they are generated through the action of kinases with distinct subcellular localizations and turned over by specific phosphatases. For example, PI(4)P localizes 
to the Golgi apparatus and the plasma membrane (PM), $\mathrm{PI}(4,5) \mathrm{P}_{2}$ and $\mathrm{PI}(3,4,5) \mathrm{P}_{3}$ to the $\mathrm{PM}$ and endosomes, $\mathrm{PI}(3,5) \mathrm{P}_{2}$ to late endosomes and $\mathrm{PI}(3) \mathrm{P}$ to early endosomes [1,2]. The recruitment of many proteins to membranes occurs via specific PIP-binding domains with different affinities for the distinct PIP species.

OSBP-related proteins constitute a ubiquitously expressed family of 12 mammalian proteins [3-5]. The ORP proteins are characterized by a lipid-binding domain designated ORD (OSBPrelated domain) in their carboxy-terminal half. The ORD of several ORPs binds cholesterol, oxysterols, or phosphatidylserine (PS), and PI(4)P or other PIPs [6-12]. In addition, most ORPs carry an aminoterminal region with a membrane-targeting pleckstrin homology (PH) domain and a two phenylalanines in an acidic tract (FFAT) motif that interacts with the integral VAMP-associated proteins (VAPs) of the ER $[13,14]$. Several ORPs are shown to localize at membrane contact sites (MCSs), zones of close apposition of two organelle limiting membranes [15]. Such sites are known to mediate the spatially restricted and tightly regulated interorganelle transfer of lipids, $\mathrm{Ca}^{2+}$ ions, and other signals [16,17]. Recent hallmark studies have established that a number of ORPs have the capacity to mediate the counter-current transport of cholesterol or phosphatidylserine (PS) in exchange for PIPs, a process in which the synthesis and hydrolysis of PIPs energizes the transport of cholesterol or PS against their concentration gradients [6,10,11,18].

ORP2 is the only mammalian ORP protein family member that exists solely as a 'short' subtype lacking a PH domain [3-5]. However, ORP2 was in certain cell lines found to target the surface of cytoplasmic lipid droplets (LD), and via interaction with the VAPs, ORP2 localizes to MCSs between the ER and LDs [19,20]. In addition, ORP2 is found in the cell cortex or at the PM [19,20](Fig. 1). Our recently published observations revealed novel functions of ORP2

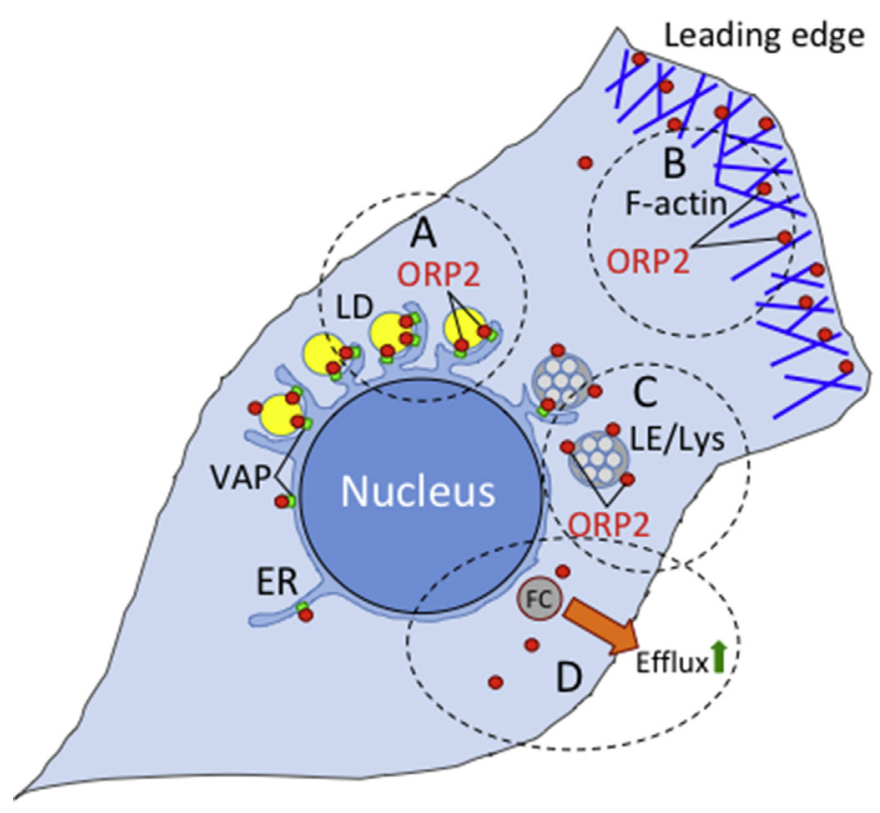

Fig. 1. A schematic image on the subcellular localizations of ORP2. ORP2 is in principle a cytosolic protein that associates with the ER via binding to the VAP proteins $[25,29]$. (A) In cells with prominent lipid droplets (LDs) ORP2 is often seen encircling the LDs [19]. When coexpressing ORP2 with the endoplasmic reticulum (ER) VAP proteins, the ORP2-VAP complexes localize at ER-LD contacts [20,29]. (B) In motile cells ORP2 is found in the cell cortex and co-localizes with the dynamic F-actin at the leading edge [21]. (C) In the present study we demonstrate that ORP2 also localizes on late endosomal/lysosomal compartments (LE/Lys). The non-LD localizations of ORP2 become obvious in cells that do not have large LDs. (D) ORP2 overexpression enhances cholesterol efflux [24,25]; FC, free cholesterol. in actin cytoskeletal regulation, Akt signalling, cellular energy metabolism, adhesion, migration and proliferation [21,22]. The actin regulatory effect of ORP2 appeared to depend on the ability of ORP2 to bind PIPs, as a PIP-binding defective mutant of ORP2 failed to induce the alterations of F-actin organization that the wild-type protein caused, and was unable to rescue a migration defect observed in ORP2 knock-out hepatocytes [21].

Of note, ORP2 is also suggested to play a role in adrenocortical steroidogenesis [23] and cellular cholesterol homeostasis [23-25]. ORP2 overexpression was reported to reduce the cellular free cholesterol by enhancing cholesterol efflux [24,25]. Furthermore, double knock-down of ORP2 and the closely related ORP1S impeded cholesterol transport from the PM to the ER [26].

A number of reports have addressed the lipid ligands of ORP2 by employing charcoal-dextran, pull-down or lipid-protein overlay assays (Table 1). The protein is shown to bind sterols [19,27], PIPs on vesicles [24] and showed affinity for phosphatidic acid and cardiolipin in an overlay assay [28]. However, previous work has not documented the affinity of ORP2 for PIPs and cholesterol, nor has its function as a putative intracellular transporter of cholesterol been addressed in detail. In this study we investigate the interactions of ORP2 with $\mathrm{PI}(4) \mathrm{P}, \mathrm{PI}(4,5) \mathrm{P}_{2}$, and $\mathrm{PI}(3,4,5) \mathrm{P}_{3}$ by surface plasmon resonance (SPR) analysis, as well as its affinity for cholesterol with a pull-down assay. The ability of ORP2 to transport dehydroergosterol (DHE) in vitro is assayed. Moreover, we employ fluorescent probes to determine the effects of ORP2 and its mutant with attenuated PIP binding on the subcellular distribution of cholesterol, and analyze the interaction of ORP2 with the related ORP1L.

\section{Materials and methods}

\subsection{Antibodies and reagents}

Anti-Xpress ${ }^{\circledR}$ antibody was purchased from Invitrogen/Thermo Scientific (Carlsbad, CA), anti-GFP antibody from Molecular Probes/ Thermo Scientific (Eugene, OR), anti-Rab7 antibody from Santa Cruz Biotechnology (Dallas, TX) and anti-LAMP1 monoclonal antibody (clone H4A3) from the Developmental Studies Hybridoma Bank (Iowa City, IA). Alexa Fluor647-dextran, BODIPY 493/503 and

Table 1

A summary of ORP2 ligand information.

\begin{tabular}{llll}
\hline Ligand & $\mathrm{K}_{\mathrm{D}}$ & Method & Reference \\
\hline 22(R)OHC & $1.4 \times 10^{-8} \mathrm{M}$ & Charcoal-dextran assay & {$[19]$} \\
$7-\mathrm{KC} \mathrm{b}^{\mathrm{b}}$ & $1.6 \times 10^{-7} \mathrm{M}$ & Charcoal-dextran assay & {$[19]$} \\
25-OHC & $3.9 \times 10^{-6} \mathrm{M}$ & Charcoal-dextran assay & {$[27]$} \\
Cholesterol & $\mathrm{ND}^{\mathrm{c}}$ & Pull-down assay & {$[19]$; This study } \\
$\mathrm{PI}(3,4,5) \mathrm{P}_{3}{ }^{\mathrm{d}}$ & $\mathrm{ND}$ & Pull-down of vesicles $^{\mathrm{f}}$ & {$[24]$} \\
& $76 \times 10^{-6} \mathrm{M}^{\mathrm{e}}$ & SPR $^{\mathrm{f}}$ & This study \\
$\mathrm{PI}(3,4) \mathrm{P}_{2}$ & $\mathrm{ND}$ & Pull-down of vesicles & [24] \\
& $\mathrm{ND}$ & Lipid-protein overlay & {$[28]$} \\
$\mathrm{PI}(3,5) \mathrm{P}_{2}$ & $\mathrm{ND}$ & Pull-down of vesicles & {$[24]$} \\
$\mathrm{PI}(4,5) \mathrm{P}_{2}$ & $\mathrm{ND}$ & Pull-down of vesicles & {$[24]$} \\
& $\mathrm{ND}$ & Lipid-protein overlay & {$[28]$} \\
& $52 \times 10^{-6} \mathrm{M}^{\mathrm{e}}$ & SPR & This study \\
$\mathrm{PI}(4) \mathrm{P}$ & $305 \times 10^{-6} \mathrm{M}^{\mathrm{e}}$ & SPR & This study \\
$\mathrm{PI}(3) \mathrm{P}$ & $\mathrm{ND}$ & Lipid-protein overlay & {$[28]$} \\
$\mathrm{Phosphatidic}$ acid & $\mathrm{ND}$ & Lipid-protein overlay & {$[28]$} \\
Cardiolipin & $\mathrm{ND}$ & Lipid-protein overlay & {$[28]$} \\
\hline
\end{tabular}

\footnotetext{
a Hydroxycholesterol.

b Ketocholesterol.

c Not determined.

d Phosphatidylinositol-3,4,5-trisphosphate.

e The $K_{d}$ values must be considered suggestive, due to substantial residual binding by ORP2(mHHK), a triple point mutant of the inositol-phosphate binding cleft.

f Surface plasmon resonance.
} 
BODIPY 558/568 C 12 neutral lipid dyes were from Molecular Probes. The Switchavidin ${ }^{\mathrm{TM}}$ used for SPR measurements was from BioNavis (Tampere, Finland) and the dic8 phosphoinositides from Echelon Biosciences (Salt Lake City, UT). TALON ${ }^{\mathbb{R}}$-resin was from Clontech/ Takara Bio (Mountain View, CA), the Strep-Tactin ${ }^{\circledR}$ resin and DDesthiobiotin from IBA Lifesciences (Goettingen, Germany), and Protein G Magnetic beads from Pierce/Thermo Scientific (Waltham, MA). $\left[1,2-{ }^{3} \mathrm{H}(\mathrm{N})\right]$ cholesterol was from PerkinElmer (Waltham, MA), egg phosphatidylcholine (PC), egg phosphatidylethanolamine (PE), porcine brain phosphatidylserine (PS), diC18:1-PI(4)P, diC18:1-PI(4,5) $\mathrm{P}_{2}$, dehydroerogosterol (DHE), 1,2-dioleoyl-sn-glycero-3-[(N-(5-amino-1-carboxypentyl)iminodiacetic acid) succinyl](DGS-NiNTA) and 18:1-dansyl-phosphatidylethanolamine from Avanti Polar Lipids (Alabaster, AL). The Silencer Select ${ }^{\circledR}$ OSBPL2 and OSBPL1A siRNAs and the Negative Control \#2 siRNA were from Ambion/Thermo Scientific (Austin, TX), and NiemannPick C1 (NPC1)-specific siRNA targeting the sequence CCAGGTTCTTGACTTACAA from Sigma-Aldrich (St. Louis, MO). Filipin (F9765) was purchased from Sigma-Aldrich (St. Louis, MO).

\section{2. cDNA constructs}

Human ORP2 wild-type, phosphoinositide-binding attenuated (mHHK; $\mathrm{H}^{178-179} \mathrm{~A}, \mathrm{~K}^{423} \mathrm{~A}$ ) and VAP-binding defective (mFFAT; $\mathrm{F}^{7-}$ ${ }^{8} \mathrm{~V}, \mathrm{D}^{9} \mathrm{~V}$ ) mutants in pmCherry-C1 (Clontech/Takara Bio) were described in Ref. [29], and GFP-tagged versions of these mutants were generated by transferring the cDNAs into the BglII/KpnI restriction sites of pEGFP-C1 (Clontech/Takara Bio). Constructs for rescue of D4H distribution after knock-down of ORP2 or ORP1L were created by generating three silent mutations in the siRNA target sequences of the corresponding cDNAs, by using QuikChange II XL mutagenesis kit (Agilent, Santa Clara, CA). The ORP2 expression construct in pcDNA4HisMax-C (Invitrogen/Thermo Scientific, Carslbad, CA) was described in Ref. [19]. The mCherry-D4H cholesterol probe plasmid was a kind gift from Prof. Gregory Fairn (Department of Biochemistry, University of Toronto, ON).

pFOLD-1 is a novel bacterial expression vector that enhances the solubility of mammalian proteins in E. coli. This vector is based on gene 9 of the T7 phage (T7 scaffolding protein) that was cloned into the pBAT4 vector [30]. Open reading frames to be expressed are fused to the C-terminus of the T7 scaffolding protein and the fusion proteins are then expressed from a T7 promoter. Shortly, the vector consists of the T7 promoter, the T7 gene 9, a His 6 or Strep tag sequence, a thrombin cleavage site, and a multiple cloning site. For production of ORP2 in E. coli, the wild-type and ORP2(mHHK) cDNAs were cloned into the BamHI site of pFOLD-His 6 and pFOLDStrep. For production of ORP2 with two Strep tags at its carboxyterminus (ORP2-2xStrep) in insect cells, the cDNA was engineered and cloned into pFastBac1 (Thermo Fisher Scientific, Waltham, MA). The pEGFP-C1-ORP1L construct is described in Ref. [31].

For Bimolecular fluorescence complementation, ORP2 cDNA was inserted into the BglII/KpnI sites of pmVN-C encoding aa 1-172 of Venus, and ORP1L cDNA into the corresponding sites in pmVC-C encoding aa 155-238 of Venus [32].

\subsection{Expression and purification of ORP2 and VAPA recombinant proteins}

For recombinant protein purification, ORP2 proteins from the pFOLD-Strep or pFOLD-His 6 vectors were produced in E. coli Rosetta 2 (DE3) (Novagen/Merck, Darmstadt, Germany). Expression was induced with $0.5 \mathrm{mM}$ IPTG at $18{ }^{\circ} \mathrm{C}$ for $24 \mathrm{~h}$. Cells were harvested and resuspended in $100 \mathrm{mM}$ Tris $-\mathrm{HCl}(\mathrm{pH} \mathrm{8.0}), 150 \mathrm{mM} \mathrm{NaCl}$, complete Protease inhibitor cocktail (Roche Diagnostics, Mannheim, Germany) and lysed by sonication. Lysates were centrifuged
(15 min $20000 \times g, 4{ }^{\circ} \mathrm{C}$ ), and the N-terminally pFOLD-Strep-tagged ORP2 proteins were purified from the supernatant using StrepTactin resin (IBA Lifesciences), and eluted with $2.5 \mathrm{mM}$ D-Desthiobiotin (IBA Lifesciences), $100 \mathrm{mM}$ Tris- $\mathrm{HCl}$ (pH 8.0) and $150 \mathrm{mM} \mathrm{NaCl}$. The pFOLD-His 6 -tagged ORP2 was purified using NiNTA agarose (Invitrogen, Carlsbad, CA) and eluted with $0.5 \mathrm{M}$ imidazole. The control proteins produced from the corresponding empty vectors were expressed and purified identically. ORP22xStrep was produced with a baculovirus vector in Spodoptera frugiperda Sf9 cells at BioMediTech Protein Technologies Core Facility (University of Tampere and the Tampere University of Technology, Tampere, Finland) and purified on the Strep-Tactin resin according to the manufacturer's instructions. The cytosolic domain of human VAPA with a carboxy-terminal $\mathrm{His}_{6}$ tag was produced in E. coli Rosetta 2 and purified on Ni-NTA Agarose (Invitrogen) with a standard protocol. Coomassie stained gels of the recombinant proteins are displayed in Supplemental Fig. S1.

\subsection{Cell culture, transfection and RNA interference}

Human HeLa cells were cultured in high glucose Dulbecco's modified Eagle's medium (DMEM, Sigma-Aldrich) supplemented with $10 \%$ FBS, $4 \mathrm{mM}$ L-glutamine, $100 \mu \mathrm{g} / \mathrm{ml}$ streptomycin and 100 $\mathrm{U} / \mathrm{ml}$ penicillin (Sigma-Aldrich). HuH7 hepatoma cells were cultured as described in Ref. [19]. Lipofectamine $2000^{\circledR}$ (Invitrogen, Carlsbad, CA) or JetPRIME ${ }^{\circledR}$ (Polyplus, New York City, NY) were used for cDNA transfections according to the manufacturer's instructions. The OSBPL2, OSBPL1A, NPC1 and control siRNAs were transfected using Oligofectamine ${ }^{\mathrm{TM}}$ (Invitrogen) by the manufacturer's protocol. Twenty-four hours after siRNA transfections, plasmids and additional $130 \mathrm{nM}$ siRNAs were transfected with Lipofectamine ${ }^{\circledR} 2000$ and incubated for another $24 \mathrm{~h}$. For the filipin stainings, siRNA transfections were carried out for $48 \mathrm{~h}$.

\subsection{Co-immunoprecipitation}

HuH7 cells were transfected with pEGFP-C1-ORP1L and pcDNA4HisMax-C-ORP2 constructs as specified above. Plain pEGFP-C1 and pcDNA4HisMax-C vectors were used as negative controls. After $24 \mathrm{~h}$, cells were washed with PBS and lysed in lysis buffer (10 mM HEPES pH 7.6, $150 \mathrm{mM} \mathrm{NaCl}, 0.5 \mathrm{mM} \mathrm{MgCl}_{2}, 10 \%$ glycerol, $0.5 \%$ Triton X-100, 0.5\% Na-deoxycholate, Protease inhibitor cocktail, Roche Diagnostics), mixed thoroughly by vortexing and incubated on ice for $10 \mathrm{~min}$. Unbroken cells and insoluble material were removed by centrifugation at $20,000 \times \mathrm{g}$ for $10 \mathrm{~min}$. The obtained lysates were mixed with $30 \mu$ l of Protein G Magnetic Beads (Pierce/Thermo Fisher Scientific) and incubated for $30 \mathrm{~min}$ on rotation at $4{ }^{\circ} \mathrm{C}$ to remove material binding unspecifically to the beads. After removing the beads, $2 \mu \mathrm{l}$ of anti-Xpress antibody (Thermo Scientific) was added and incubated for $24 \mathrm{~h}$ on rotation at $4{ }^{\circ} \mathrm{C}$. The next day, $30 \mu \mathrm{l}$ of Protein G Magnetic Beads were added and the mixture was incubated for $2 \mathrm{~h}$ on rotation at $4{ }^{\circ} \mathrm{C}$. The beads were then washed three times with lysis buffer, resuspended in $45 \mu \mathrm{l}$ Laemmli sample buffer and boiled for $5 \mathrm{~min}$. The bound proteins were detected with anti-GFP (Thermo Scientific) and antiXpress antibodies.

\subsection{Cholesterol binding assay}

The specific affinity of purified recombinant ORP2 to cholesterol was defined with an assay described previously [33] with minor modifications. Recombinant pFOLD-His 6 was used as a negative control. pFOLD-His ${ }_{6}-\mathrm{ORP} 2$ and the pFOLD-His 6 were incubated at a $70 \mathrm{nM}$ concentration with $20-400 \mathrm{nM}$ mixtures of unlabeled and $\left[{ }^{3} \mathrm{H}\right]$ cholesterol for $2 \mathrm{~h}$ at room temperature in $20 \mathrm{mM}$ Tris ( $\left.\mathrm{pH} 7.4\right)$, 
$100 \mathrm{mM} \mathrm{KCl}, 0.05 \%$ Triton X-100 or 0.1\% CHAPS (Amresco, Boise, ID). Subsequently, $20 \mu 1$ TALON $^{\circledR}$ resin (Takara Bio) was added in each sterol-protein mix and incubated for 30 min at RT with constant rotation. The supernatants were removed and the beads were washed 3 times with the above buffers. The amounts of bound ORP2-cholesterol complex were determined by liquid scintillation counting.

\subsection{Dehydroergosterol (DHE) transfer assays}

The ability of ORP2 to transfer DHE was assessed essentially as described in Ref. [10]. The assays donor liposomes $\left(\mathrm{L}_{\mathrm{d}}\right)$ composed of $75 \mathrm{~mol} \%$ egg-PC, 5 mol\% porcine brain PS, 2 mol\% 18:1 DGS-NiNTA, $18 \mathrm{~mol} \%$ DHE, and the acceptors of $73.5 \mathrm{~mol} \%$ egg-PC, $19 \mathrm{~mol} \%$ egg PE, $5 \mathrm{~mol} \%$ porcine brain PS, and $2.5 \mathrm{~mol} \%$ dansyl-PE. The assay buffer was $50 \mathrm{mM}$ HEPES, pH 7.2, $120 \mathrm{mM}$ K-acetate, $1 \mathrm{mM} \mathrm{MgCl} 2$ (HKM buffer). In some assays, 2 mol\% di18:1-PI(4)P $\left(\mathrm{L}_{\mathrm{a} 1}\right)$ or di18:1$\mathrm{PI}(4,5) \mathrm{P}_{2}\left(\mathrm{~L}_{\mathrm{a} 2}\right)$ was included in the acceptor liposomes, with a corresponding reduction in the $\mathrm{mol} \%$ of egg PC. The assays contained $10 \mathrm{nmol} \mathrm{L}_{d}$ and $10 \mathrm{nmol} \mathrm{L}_{\mathrm{a}}$ lipid in a total volume of $150 \mu \mathrm{l}$. VAPA$\mathrm{His}_{6}$ ( 50 pmol per assay) was added to the donor liposomes and incubated for $30 \mathrm{~min}$ at room temperature before the assays. The DHE-dansyl-PE FRET signal was recorded at 3-min intervals for 60 min on an EnSpire fluorometer/multimode plate reader (Perkin Elmer) with the excitation and fluorescence detection wavelengths of 310 and $525 \mathrm{~nm}$, respectively. In the transfer assays, $15 \mathrm{pmol}$ (final conc. $100 \mathrm{nM}$ ) plain pFOLD-His 6 , pFOLD-His 6 -ORP2, ORP22xStrep, OSBP (a kind gift from Prof. Bruno Antonny, Institut de Pharmacologie Moléculaire et Cellulaire, Valbonne, France) were added per reaction.

\subsection{Dynamic light scattering (DLS) measurements}

The liposome tethering ability of ORP2 was studied by DLS using a Zetasizer APS instrument (Malvern, UK). The assay was designed as described in Ref. [10], and liposomes identical to those used in the DHE transfer assay $\left(\mathrm{L}_{\mathrm{d}}, \mathrm{L}_{\mathrm{a} 1}, \mathrm{~L}_{\mathrm{a} 2}\right)$ were used. $\mathrm{L}_{\mathrm{d}}(25 \mu \mathrm{M})$ were preincubated with $200 \mathrm{nM}$ of VAPA-His ${ }_{6}$ for $30 \mathrm{~min}$ at room temperature, mixed with $\mathrm{L}_{\mathrm{a} 1}(25 \mu \mathrm{M})$ or $\mathrm{L}_{\mathrm{a} 2}(25 \mu \mathrm{M})$ in HKM buffer, following addition of $250 \mathrm{nM}$ of plain pFOLD-Strep, pFOLD-StrepORP2, ORP2-2x-Strep or OSBP. The liposome aggregation was measured at $30^{\circ} \mathrm{C}$ at 2-min intervals, each time point consisting of 13 autocorrelation runs. The data was collected and analyzed by Malvern software by using cumulate method, i.e. the particle diameter was fitted as intensity and polydispersity index-based Gaussian distribution.

\subsection{Preparing surface plasmon resonance (SPR) sensor chip surfaces}

All SPR experiments were performed with an MP-SRP NAVI $220 \mathrm{~A}$ instrument (BioNavis, Tampere, Finland) equipped with 2 flow channels. The binding affinities of ORP2 for PIPs were assessed by using functionalized biotin-coated gold sensors (BioNavis). Prior to the experiments, the sensors were coated with Switchavidin ${ }^{\mathrm{TM}}$ (a neutralized avidin mutant for reversible binding, BioNavis) to create an affinity surface for the strep-tagged recombinant proteins. The Switchavidin was immobilized onto the sensor chip surface according to manufacturer's instructions. Subsequently, pFOLD-Strep-ORP2 or pFOLD-Strep-ORP2(mHHK) (flow channel 1) and pFOLD-Strep as reference (flow channel 2) were allowed to form a complex with the biotin-Switchavidin surface. The proteins were immobilized using a flow rate of $20 \mu \mathrm{l} / \mathrm{min}$ and a protein concentration of $50 \mu \mathrm{g} / \mathrm{ml}$ until the binding reached saturation. The unbound proteins were removed by washing the sensor surface with a $20 \mathrm{mM}$ HEPES, $150 \mathrm{mM} \mathrm{NaCl}$ (pH 7.4) running buffer until the SPR signal was stabilized.

\subsection{Surface plasmon resonance (SPR) measurements}

The binding affinities of diC8-PI(4)P, $-\mathrm{PI}(4,5) \mathrm{P}_{2},-\mathrm{PI}(3,4,5) \mathrm{P}_{3}$ to ORP2 were determined in real-time using an MP-SPR NAVI 220A instrument (BioNavis) which utilizes the Kretchmann configuration to excite surface plasmons. The whole SPR angular spectrum was measured between 60 and $75^{\circ}$, and scanned with a laser wavelength of $670 \mathrm{~nm}$. All measurements were carried out by using a $20 \mathrm{mM}$ HEPES, $150 \mathrm{mM} \mathrm{NaCl}$ ( $\mathrm{pH} 7.4$ ) running buffer at $20^{\circ} \mathrm{C}$ with a flow rate of $20 \mu \mathrm{l} / \mathrm{min}$. The SPR sensorgrams were measured for a series of injections of PIPs $(0.33-100 \mu \mathrm{M})$ at growing concentrations. To distinguish specific affinities from possible unspecific binding and the bulk effect, i.e. the refractive index change caused by merely rising PIP or protein concentrations, pFOLD-Strep was used as a control. Samples were injected sequentially through the two parallel SPR flow channels containing pFOLD-Strep-ORP2 or pFOLD-Strep-ORP2(mHHK) (flow channel 1) and pFOLD-Strep as the reference (flow channel 2). The SPR sensorgram from the reference channel was subtracted from the ORP2 channel in realtime. The data was collected with the MP-SPR Navi Control 4.2.5 software (BioNavis) and processed using the MP-SPR Navi Data Viewer 4.2.5 software (BioNavis). The dissociation constants were determined by using the TraceDrawer 1.7 software (RidgeView Instruments $\mathrm{Ab}$, Uppsala, Sweden). The quality of the fit was determined with $\chi^{2}$ value (Supplemental Table S1).

\subsection{Fluorescence microscopy}

The fluorescent labels were visualized with a Zeiss Axio Observer Z1 microscope equipped with PInApo x63/1.40 oil DICII objective and a Colibri LED light source (Zeiss, Oberkochen, Germany). Images were taken with a AxioCam HRm camera and recorded with Zen 2 v.2.0.0 software (Zeiss). For live cell imaging, a stage top incubation chamber (Zeiss) with temperature set to $37^{\circ} \mathrm{C}$ and $\mathrm{CO}_{2}$-independent cell culture medium (Gibco/Thermo Scientific) were used. Adobe Photoshop CC 2017 (Adobe, San Jose, CA), Imaris 9.1 (Bitplane, Zürich, Switzerland) and Image J/Fiji (National Institutes of Health, Bethesda, MD) were used for image processing and analysis. Colocalization analysis was performed with ImageJ coloc2 function and determined by Pearson's correlation coefficient.

\subsection{Bimolecular fluorescence complementation (BiFC)}

HeLa cells were double transfected for $24 \mathrm{~h}$ with pmVN-C-ORP2 and pmVC-C-ORP1L, or a single BiFC construct was cotransfected with an empty vector as a negative control. In some experiments Alexa Fluor647-dextran was internalized for $90 \mathrm{~min}$ and chased for $1 \mathrm{~h}$ to label late endosomes/lysosomes, or these organelles were stained with anti-Rab7. LD were stained with BODIPY 558/568 $C_{12}$. The cells were fixed and processed for fluorescence microscopy as described above.

\subsection{Staining of cholesterol with filipin}

HeLa cells were transfected for $48 \mathrm{~h}$ with control or ORP2 siRNA using HiPerFect (Qiagen, Hilden, Germany). After fixation with $4 \%$ paraformaldehyde for $15 \mathrm{~min}$, cells were stained with $0.5 \mathrm{mg} / \mathrm{ml}$ filipin in 1\% BSA/PBS for $1 \mathrm{~h}$, stained with anti-LAMP1 (clone H4A3) and with secondary antibodies. Cells were imaged with a Nikon (Tokyo, Japan) Eclipse Ti-E inverted microscope equipped with a $40 x / 0.75$ objective. Mean filipin fluorescence intensity per cell and 
in LAMP1 positive organelles was quantified using ImageJ/Fiji software, and statistical significance of differences was evaluated with Student's $t$-test.

\section{Results}

\subsection{Binding of phosphoinositides and cholesterol to ORP2}

We recently proposed that ORP2 is involved in regulation of adhesion, migration and proliferation of HuH7 hepatoma cells functions that were reliant on the ability of ORP2 to bind PIPs [21]. Although ORP2 lacks the hallmark PIP-sensing PH domain, it encompasses an ORD domain, which in several ORPs has the capacity to accommodate and extract PI(4)P and other PIPs [6,10,34]. Noteworthy, ORP2 was previously shown to interact with the head groups of long-chain phosphoinositides in vitro on vesicle surfaces [24]. However, the kinetic analysis of PIP binding to the ORD of ORP2 is lacking.

To examine the specific binding affinities of $\mathrm{PI}(4) \mathrm{P}, \mathrm{PI}(4,5) \mathrm{P}_{2}$, and $\mathrm{PI}(3,4,5) \mathrm{P}_{3}$ to ORP2 in real-time, we used the MP-SPR NAVI 200 instrument. Recombinant pFOLD-Strep-ORP2 was attached on Switchavidin ${ }^{\mathrm{TM}}$-coated SPR sensor chips, and aqueous soluble short-chain dic8-PIPs were introduced to the protein via a continuous flow system. The binding curves for 10,33 and $100 \mu \mathrm{M}$ concentrations of each PIP are presented in Fig. 2. ORP2 bound $\mathrm{PI}(4,5) \mathrm{P}_{2}$ at $52 \pm 13 \mu \mathrm{M}(\mathrm{n}=3), \mathrm{PI}(3,4,5) \mathrm{P}_{3}$ at $76 \pm 11 \mu \mathrm{M}(\mathrm{n}=3)$, and $\mathrm{PI}(4) \mathrm{P}$ at $305 \pm 155 \mu \mathrm{M}(\mathrm{n}=3)$ apparent $\mathrm{K}_{\mathrm{d}}$ (the full data is displayed in Supplemental Table S1). To investigate the PIP binding defect of ORP2(mHHK), a triple point mutant of the inositolphosphate-binding cleft, we also purified a pFOLD-Strep fusion of this protein and subjected it to PIP binding analyses by SPR. The SPR signals of ORP2(mHHK) with all three PIPs were attenuated, but the PIP binding was not abolished (Supplemental Fig. S2), suggesting that the observed signals may involve an unspecific aspect or partial binding at a site different from the ORD pocket. Therefore, the $K_{d}$ values determined above must be interpreted with caution.

We have previously suggested that ORP2 has the capacity to bind cholesterol [19], based on a qualitative pull-down assay in which radiolabeled cholesterol solubilized with cyclodextrin was employed as a binding substrate. The assay, however, did not allow quantitative assessment of the ligand interaction. Since the SPR assay is not compatible with the detergent conditions required to solubilize cholesterol, we employed a pull-down assay previously described by the group of N. Ridgway [33]. In this assay $\left[{ }^{3} \mathrm{H}\right]$ cholesterol is solubilized with Triton $\mathrm{X}-100$ and His6-ORP with bound $\left[{ }^{3} \mathrm{H}\right]$ cholesterol is pulled down with TALON $^{\circledR}$ resin. The pFOLD-His ${ }_{6}$-ORP2 failed to bind $\left[{ }^{3} \mathrm{H}\right]$ cholesterol over the background level of plain pFOLD-His 6 in the presence of $0.05 \%$ Triton X100 . Specific binding of cholesterol by ORP2 was, however, detected when the cholesterol was instead solubilized with 0.1\% CHAPS, a zwitterionic detergent (Fig. 3A). However, saturation was not reached with the present assay, so we were unable to determine a precise $K_{d}$ for the ORP2-cholesterol interaction.

\subsection{ORP2 alone fails to enhance sterol transfer in vitro}

To analyze whether recombinant ORP2 is capable of transferring sterol between vesicles in vitro, we employed a transfer assay previously employed to measure the activity of OSBP [10]. Here, the fluorescent sterol dehydroergosterol (DHE) is transferred from donor vesicles to acceptors that contain the fluorescence resonance energy transfer (FRET) partner dansyl-PE, resulting in the emission of fluorescence at $525 \mathrm{~nm}$. VAPA-His 6 was added to the donor vesicles $\left(\mathrm{L}_{\mathrm{d}}\right)$ containing a Ni-NTA lipid to capture the VAP, since like OSBP, ORP2 carries a FFAT motif for interaction with VAPs. PI(4)P
A

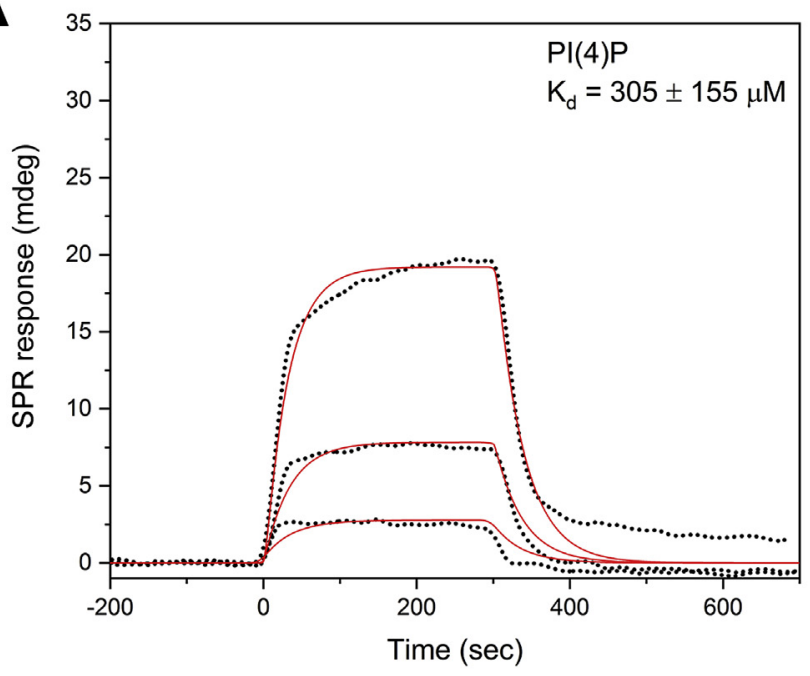

B

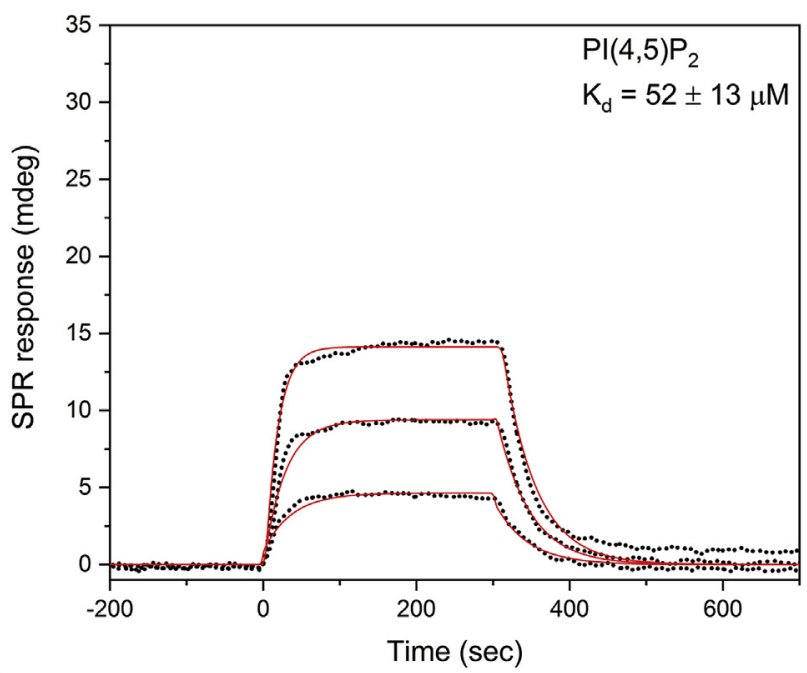

C

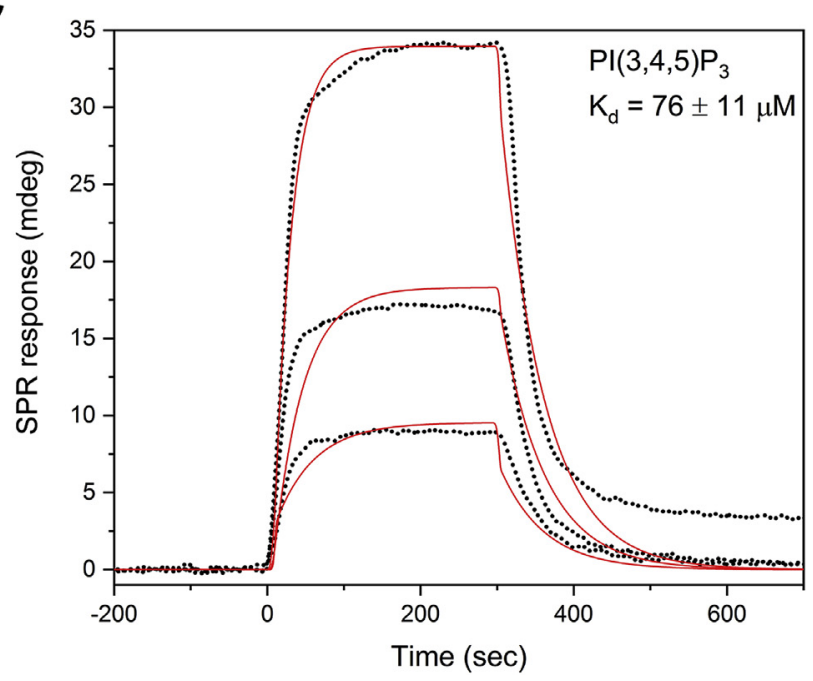

Fig. 2. Kinetic analysis of $\mathrm{PI}(4) \mathrm{P}, \mathrm{PI}(4,5) \mathrm{P}_{2}$, and $\mathrm{PI}(3,4,5) \mathrm{P}_{3}$ binding to $\mathrm{ORP} 2$ determined by SPR in real-time. Recombinant pFOLD-Strep-ORP2 was attached on Switchavidin ${ }^{\mathrm{TM}}$ coated SPR sensor chips, and water-soluble diC8-PIPs were directed through the flow channel at a flow rate of $20 \mu \mathrm{l} / \mathrm{min}$ at RT. PIP concentrations of $10 \mu \mathrm{M}, 33 \mu \mathrm{M}$ and $100 \mu \mathrm{M}$ were used. The SPR sensorgrams were fitted with kinetic analysis of a one-site binding model with the TraceDrawer 1.7 software. The fitted binding curves of ORP2 and $(\mathrm{A}) \mathrm{PI}(4) \mathrm{P},(\mathrm{B}) \mathrm{PI}(4,5) \mathrm{P}_{2}$, and $(\mathrm{C}) \mathrm{PI}(3,4,5) \mathrm{P}_{3}$ are plotted against time. Mean $\mathrm{K}_{d}$ values $\pm S D(n=3)$ are indicated. 
A

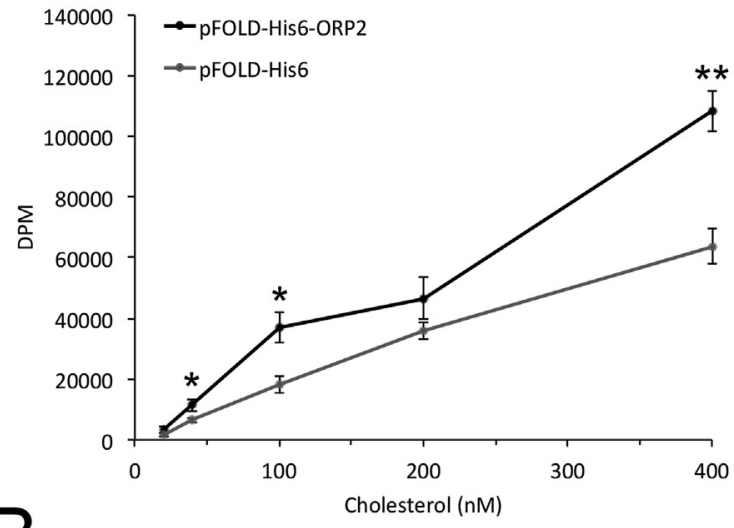

B
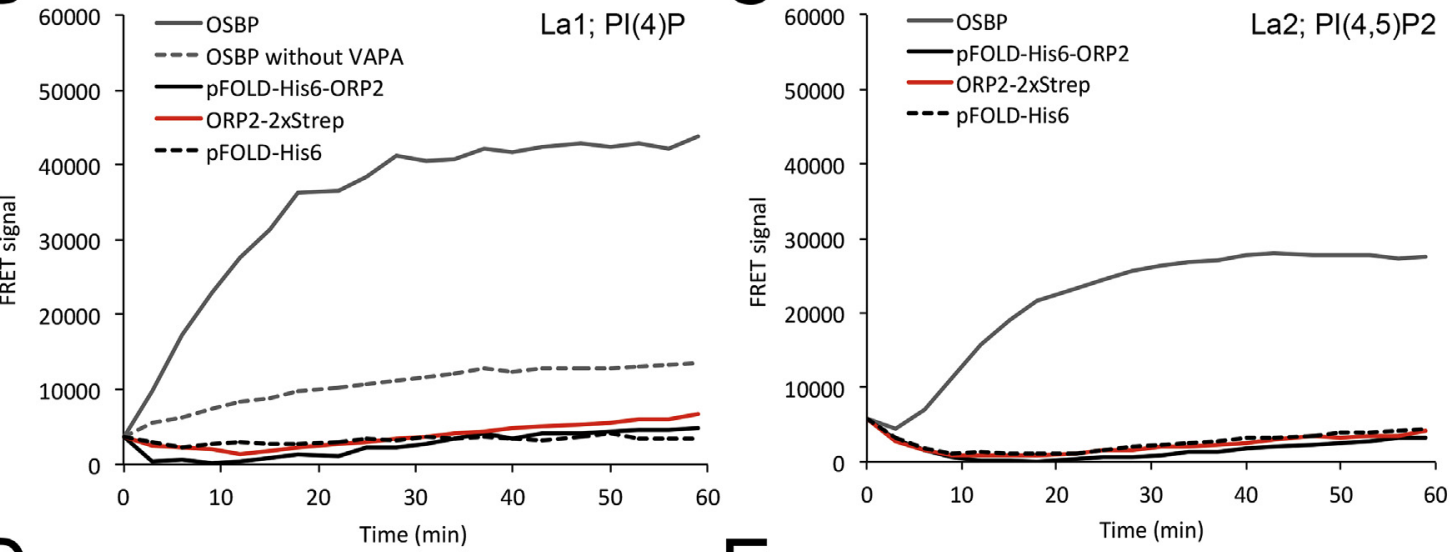

$\mathrm{D}$
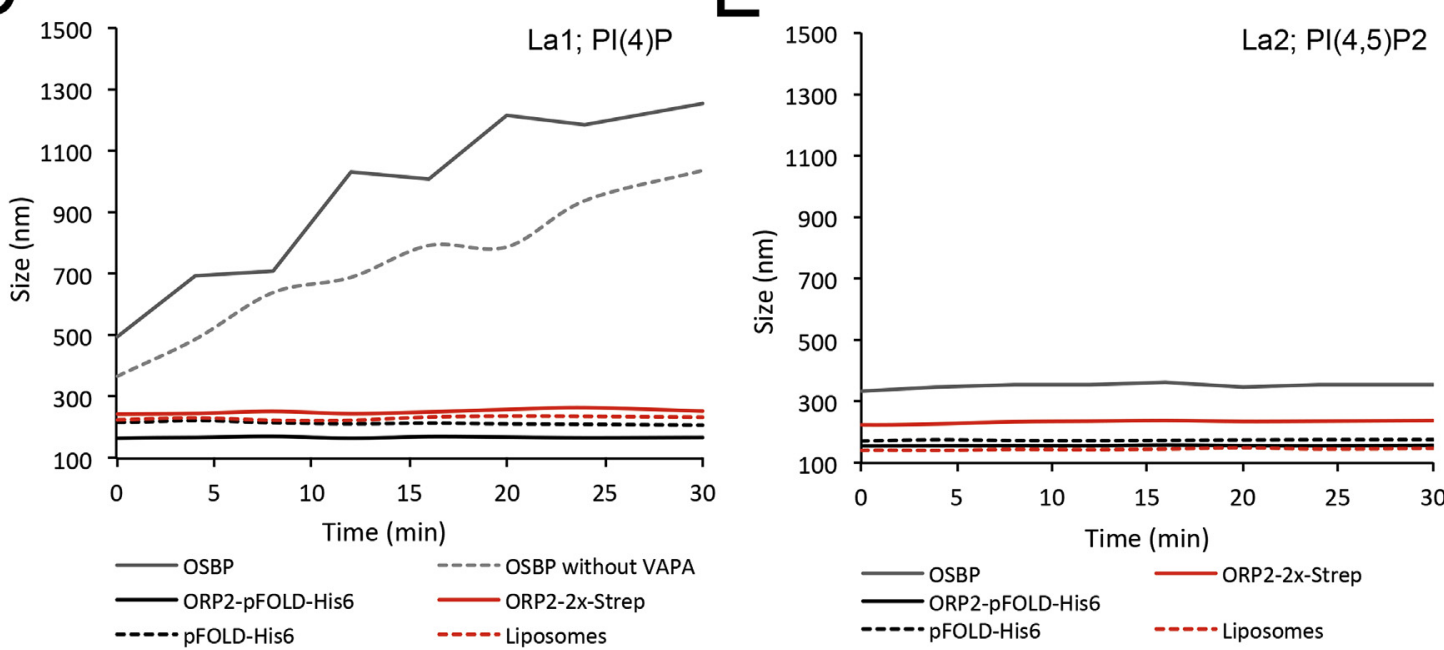

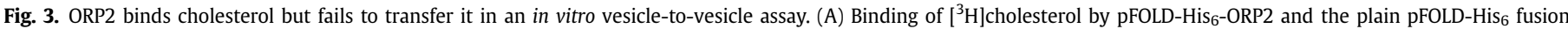

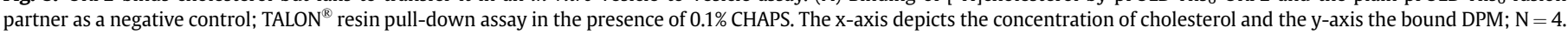

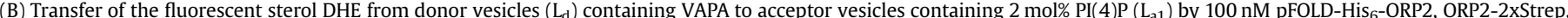

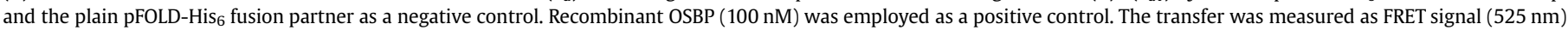

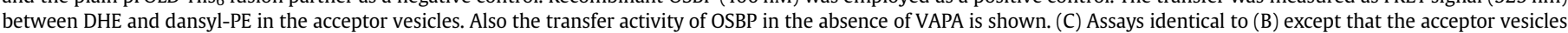

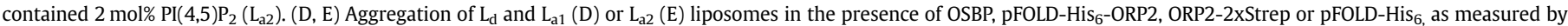
dynamic light scattering.

$\left(\mathrm{L}_{\mathrm{a} 1}\right)$ or $\mathrm{PI}(4,5) \mathrm{P}_{2}\left(\mathrm{~L}_{\mathrm{a} 2}\right)$ were added to the acceptor vesicles to mediate the interaction of the donor-transfer protein complex with the acceptors and to provide a potential counter-transport substrate [10]. In this assay, OSBP transferred DHE, and the reaction was enhanced by the presence of VAPA, evidencing for specific protein-mediated sterol transfer (Fig. $3 \mathrm{~B}$ and $\mathrm{C}$ ). However, the
pFOLD-His6-ORP2 fusion protein failed to show DHE transfer activity (Fig. 3B and C). We suspected that the amino-terminal pFOLD-His 6 fusion partner present on the protein, which could not be removed due to protein yield and solubility problems, might inhibit a putative DHE transfer activity of ORP2. We therefore produced and purified carboxy-terminally tagged ORP2-2xStrep in 
insect cells, and tested this protein in the DHE transfer assay. Similar to the pFOLD-His ${ }_{6}-\mathrm{ORP} 2$, it failed to show transfer activity (Fig. 3B and C).

In order to investigate whether the lack of transfer activity by ORP2 might be due to inability to cluster donor $\left(\mathrm{L}_{\mathrm{d}}\right)$ and acceptor vesicles, we carried out dynamic light scattering (DLS) experiments with vesicles incubated in the absence or presence of OSBP or ORP2. In these experiments the acceptor vesicles contained $2 \mathrm{~mol} \%$ of either $\mathrm{PI}(4) \mathrm{P}\left(\mathrm{L}_{\mathrm{a} 1}\right)$ or $\mathrm{PI}(4,5) \mathrm{P}_{2}\left(\mathrm{~L}_{\mathrm{a} 2}\right)$. The results showed that OSBP induced a time-dependent clustering of the vesicles containing $\mathrm{PI}(4) \mathrm{P}\left(\mathrm{L}_{\mathrm{a} 1}\right)$ but not those containing $\mathrm{PI}(4,5) \mathrm{P}_{2}\left(\mathrm{~L}_{\mathrm{a} 2}\right)$ (Fig. 3D and $\mathrm{E}$ ). However, no clustering of the liposomes was induced by the ORP2 fusion proteins. These data suggest that ORP2 alone is not able to cluster vesicles.

\subsection{Role of the PIP interaction in the subcellular targeting of ORP2}

To analyze the putative role of ORP2's association with cellular PIPs in the localization of the protein, the wild-type (wt) or PIPbinding attenuated (mHHK) mutant ORP2 were visualized in HeLa cells. Previous reports showed localization of ORP2 to LDs in A431, HuH7 or fatty acid-loaded HeLa TRex cells. Under certain conditions it was also detected at the PM or in the cell cortex $[19,20]$. In HeLa cells under standard culture conditions the wt ORP2 displayed a diffuse distribution with cytosolic, ER and occasional PM aspects, but it also frequently encircled LDs identified by internalized BODIPY 558/568 $\mathrm{C}_{12}$ (Fig. 4A). Interestingly, ORP2(mHHK) displayed an enhanced targeting to LDs (Fig. 4B), and quantification confirmed a significant difference in the localization of the wt and mutant proteins (Fig. 4C). The above results are consistent with a model in which the non-LD targeting of ORP2 is mediated via phosphoinositide binding, and the ORP2(mHHK) mutant therefore shows increased secondary targeting to the LDs.

\subsection{ORP2 interacts with ORP1L}

We recently reported an ORP2 interactome analysis in $\mathrm{HuH7}$ hepatoma cells. The analysis suggested 107 putative new interaction partners for ORP2, among which was ORP1L [21]. ORP2 and ORP1L belong to the same ORP subfamily II and share close sequence homology in their ORD domain [5]. ORP1L localizes to late endosomes (LEs) and is suggested to play multiple roles in LE motility, fusion, autophagy, and cholesterol trafficking from LEs to the ER or in the opposite direction [35-40].

The physical association of ORP2 with ORP1L was confirmed by anti-Xpress co-immunoprecipitation (IP) in $\mathrm{HuH7}$ cells overexpressing Xpress-ORP2 and GFP-ORP1L constructs. The antiXpress-ORP2 precipitates also contained ORP1L detectable with anti-GFP antibody, while the negative controls with the plain Xpress or GFP vectors lacked the signal (Fig. 5A), supporting a specific interaction of ORP2 with ORP1L.

To further study the putative interaction of ORP2 with ORP1L, we employed the BiFC technique [41], in which ORP2 and ORP1L were each fused with a non-fluorescent partial fragment of Venus. When the two proteins interact or come to close proximity, the Venus fragments complement each other, resulting in a fluorescent signal at the subcellular compartment where the interaction occurs. Here, ORP2 and ORP1L displayed in HeLa cells a strong and specific BiFC signal at compartments which represented late endosomes based on co-localization with Rab7 (Fig. 5B). The signal did not co-localize with the LD marker BODIPY 558/568 $C_{12}$ (Fig. 5C). Co-localization of the ORP2-ORP1L BiFC signal with Rab7 and BODIPY 558/568 $C_{12}$ was quantified, showing a markedly higher Pearson's correlation coefficient for Rab7 $(\rho=0.91)$ than for the LD dye $(\rho=0.20)$ (Fig. 5B and C).
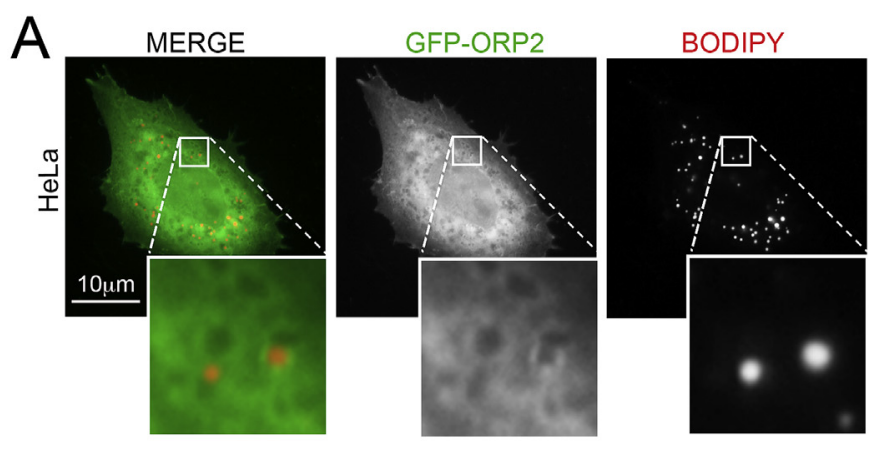

B

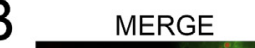

GFP-ORP2(mHHK)

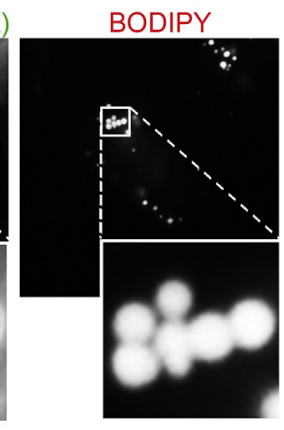

C
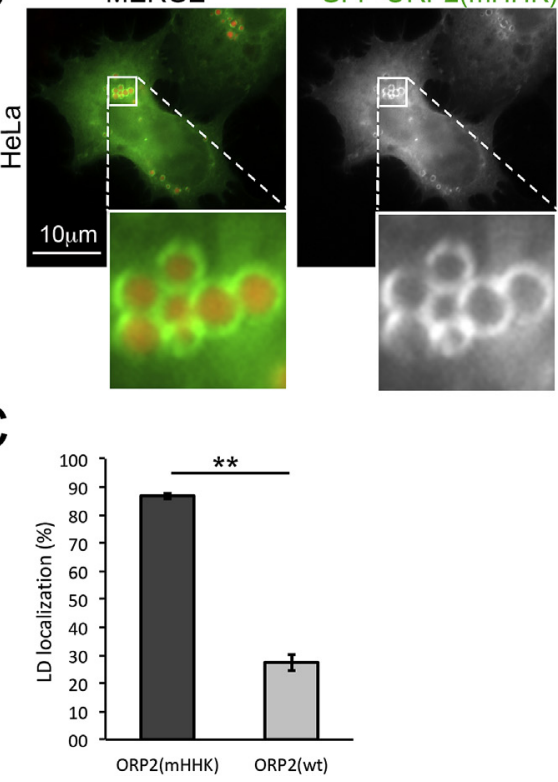

Fig. 4. ORP2 mutant with attenuated PIP binding shows enhanced targeting to lipid droplets. HeLa cells transfected for $24 \mathrm{~h}$ with wt ORP2 (A) or ORP2(mHHK) (B) were subjected to LD staining by using BODIPY 558/568 $C_{12}$. (C) Quantification of the LD localization. For each construct approximately 100 cells were analyzed visually, and the proportion of cells with prominent LD localization of ORP2 (threshold of 5 ORP2encircled LDs) is expressed as percentage $\left(n=3 ;{ }^{* *} \mathrm{p}<0.01\right)$.

To visualize the subcellular distribution of ORP2 and ORP1L in the absence of the Venus fragments employed for the BiFC, mCherry-ORP2 and GFP-ORP1L were co-expressed and imaged in live HeLa cells (Fig. 5D; Video 1; Supplemental Fig. S3). Interestingly, ORP2 and ORP1L were found to partially co-localize in perinuclear ring-like structures. These structures represent LEs/ lysosomes, since they contained the internalized marker Alexa Fluor647-dextran (Fig. 5D). A majority of ORP2 and ORP1L resided on distinct organelles, which however, dynamically communicated with each other, resulting in their transient, and sometimes more stable co-localization (Videos $1 \mathrm{~A}-\mathrm{C}$ ). Of note, ORP2 did not only localize on LEs in the presence of overexpressed ORP1L, but it was, in addition to a LD localization, frequently detectable on late endocytic compartments also when expressed alone (Fig. 5E).

Supplementary video related to this article can be found at https://doi.org/10.1016/j.biochi.2018.12.013.

\subsection{ORP2 causes redistribution of the subcellular pools of cholesterol}

The putative involvement of ORP2 in regulating cellular cholesterol homeostasis [24,25] and its interaction with ORP1L prompted us to study whether ORP2 might affect the intracellular 


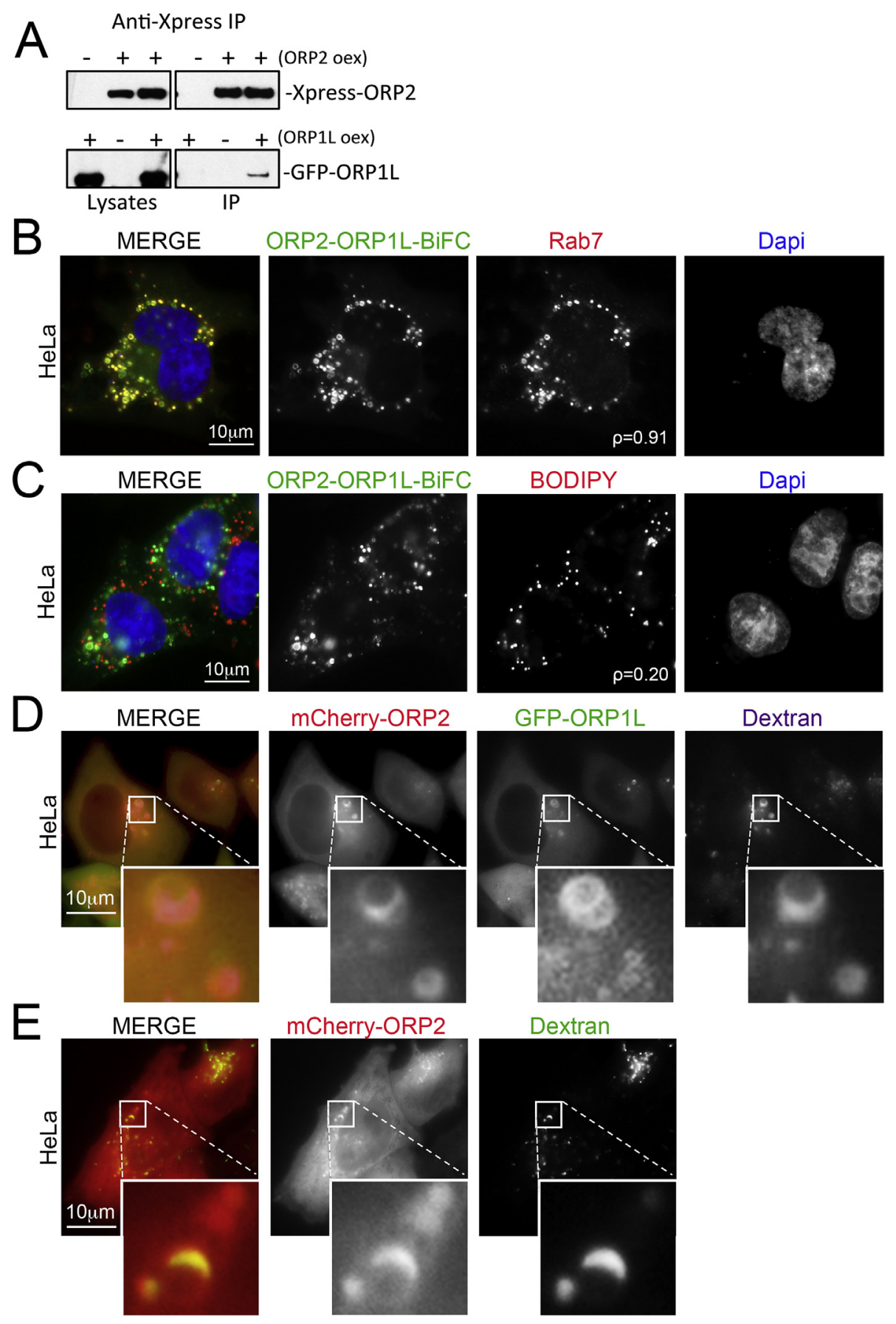

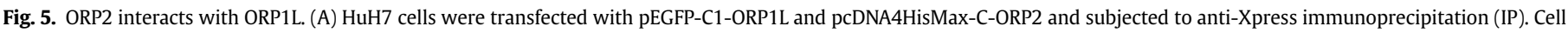

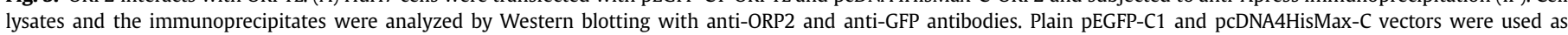

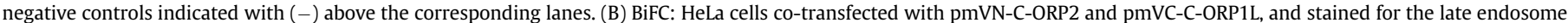

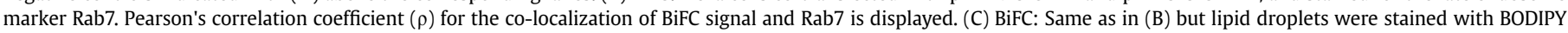

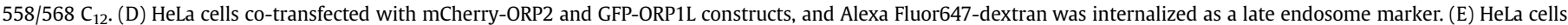
transfected with mCherry-ORP2 alone, with late endocytic compartments labeled with internalized Alexa Fluor647-dextran. Nuclei were visualized with DAPI in B-C.

distribution of cholesterol. To this end, the protein or its PIPbinding attenuated mutant ORP2( $\mathrm{mHHK}$ ) were co-expressed in HeLa cells with a fluorescent cholesterol probe, the cholesterolbinding domain 4 of theta-toxin fused with mCherry (mCherryD4H) [42]. In cells expressing GFP alone as a control, the D4H probe distributed between the PM and punctate/vesicular endosomes (Fig. 6A) as previously described [42]. However, in HeLa cells overexpressing wt ORP2, the D4H probe localized mainly at the PM and markedly less on the endosomal compartments as compared to the controls (Fig. 6B). Interestingly, ORP2(mHHK) accumulated the $\mathrm{D} 4 \mathrm{H}$-accessible pool of cholesterol in perinuclear endosomes, drastically reducing the $\mathrm{D} 4 \mathrm{H}$ probe intensity at the PM (Fig. 6C), suggesting a perturbation of intracellular cholesterol trafficking. Of note, the organelles with accumulated $\mathrm{D} 4 \mathrm{H}$ probe did not colocalize with a LD marker (Fig. 6D). Quantification of D4H localization revealed significant differences between the GFP control, the wt ORP2, and ORP2(mHHK) (Fig. 6E).

To determine whether these effects of ORP2 reflect a function of 


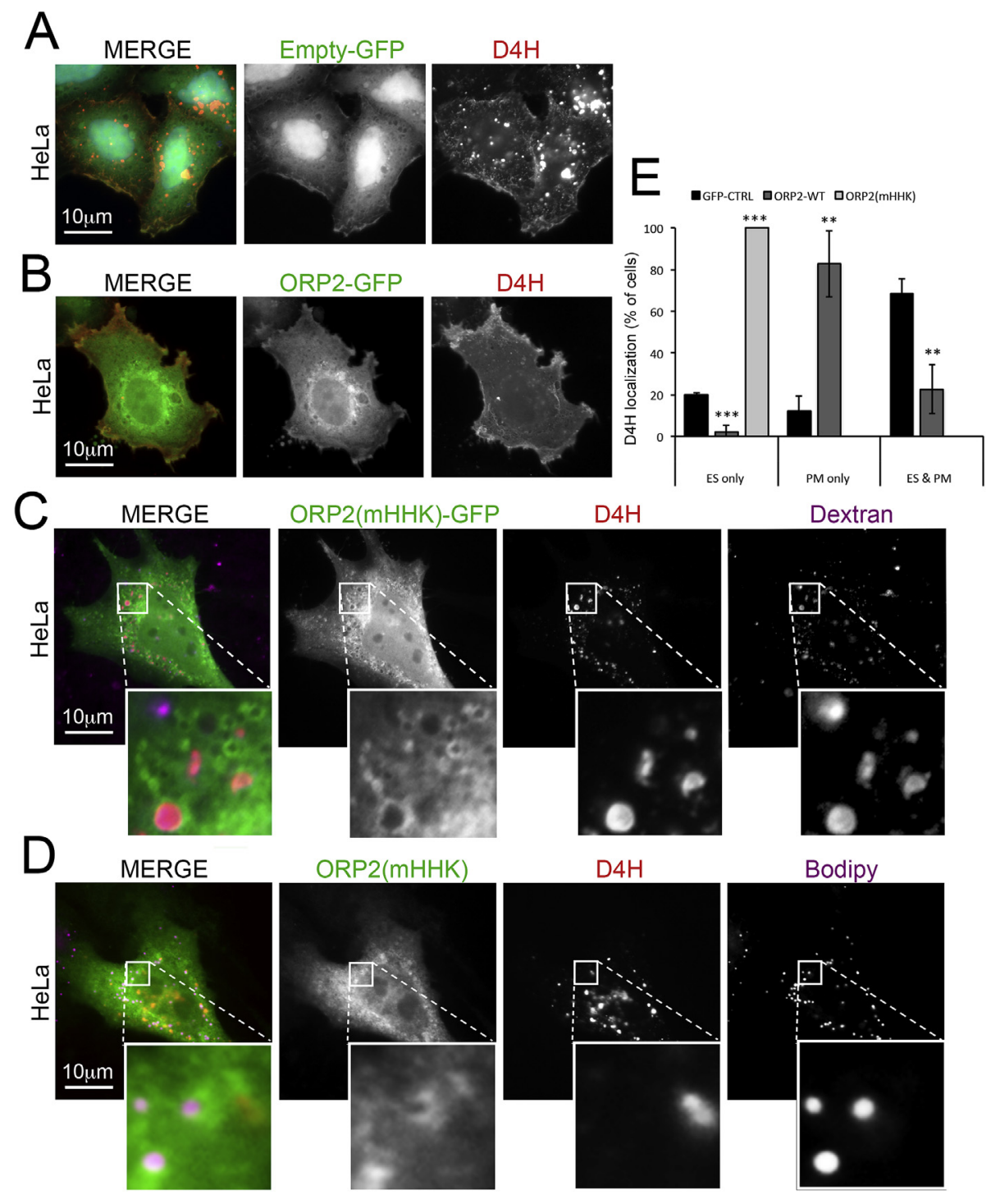

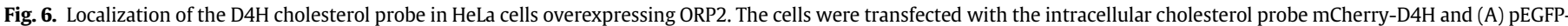

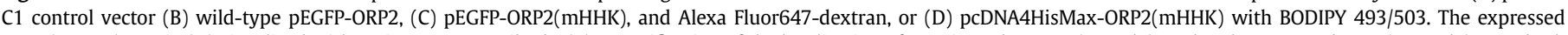

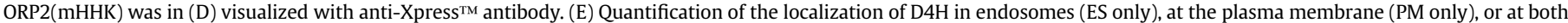
(ES \& PM); approximately 30 transfected cells were calculated for each transfection $\left(\mathrm{n}=3\right.$ for each data point); ${ }^{* *} \mathrm{p}<0.01$, ${ }^{* * *} \mathrm{p}<0.001$, comparison to the GFP control.

the endogenous ORP2 protein, we carried out siRNA-mediated knock-down of ORP2 in HeLa cells. In addition, since LE accumulation of cholesterol is reported to occur in ORP1L-null cells [40], we knocked down ORP1L for a comparison. In cells transfected with non-targeting control siRNA, the D4H probe distributed between the PM and endosomes (Fig. 7A). Interestingly, when the $\mathrm{D} 4 \mathrm{H}$ probe was imaged in the ORP2 or ORP1L knock-down cells, a majority of the probe was found accumulated in the perinuclear endosomes. Importantly, this D4H phenotype was rescued when siRNAresistant ORP2 or ORP1L cDNA expression constructs were introduced into the respective knock-down cells (Fig. 7B), demonstrating that the perinuclear D4H accumulation was caused by the depletion of the ORPs. The D4H phenotype was quantified in both the siRNA transfected and the rescued HeLa cells, confirming significant differences in distribution of the cholesterol probe between ORP2 and ORP1L knock-down vs. control cells, as well as the rescue effects (Fig. 7C and D).

Since the $\mathrm{D} 4 \mathrm{H}$ probe requires a threshold concentration to associate with membrane surfaces and may not faithfully reflect the distribution of cholesterol [42], we investigated the effect of ORP2 knock-down on the subcellular distribution of cholesterol by using the cholesterol-binding dye filipin (Fig. 8A). Knock-down of Niemann-Pick C1 (NPC1) protein, a well characterized late endosomal cholesterol transporter [43], was carried out as a reference. The filipin staining revealed a similar increase of the total cellular filipin signal and the signal in LAMP1-positive late endosomes/lysosomes in both the ORP2 and the NPC1 knock-down cells (Fig. 8B and $\mathrm{C}$ ), reinforcing the interpretation that ORP2 indeed functions in the egress of cholesterol from LEs/lysosomes.

\section{Discussion}

In the present study we addressed the ligand specificity and function of ORP2. Our SPR data demonstrates specific binding of $\mathrm{PI}(4,5) \mathrm{P}_{2}, \mathrm{PI}(3,4,5) \mathrm{P}_{3}$ and $\mathrm{PI}(4) \mathrm{P}$ to ORP2. The apparent affinities are somewhat lower than those recently determined for the ORD domains of ORP5 and -8 [34]. The SPR signals of a triple point mutant affecting the inositol-phosphate-binding cleft of ORPs, ORP2 


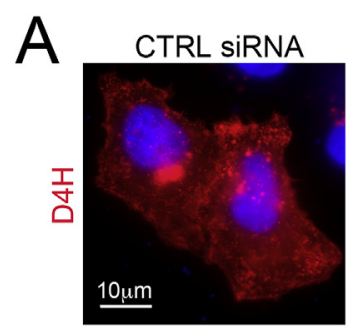

B

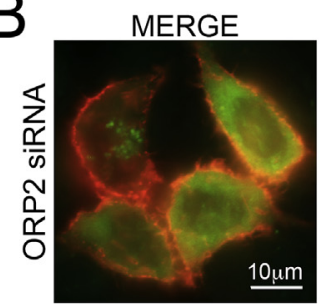

MERGE

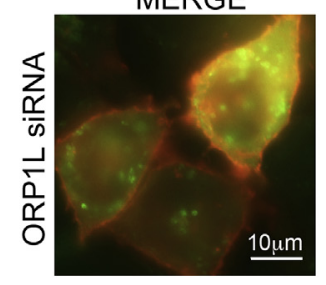

C
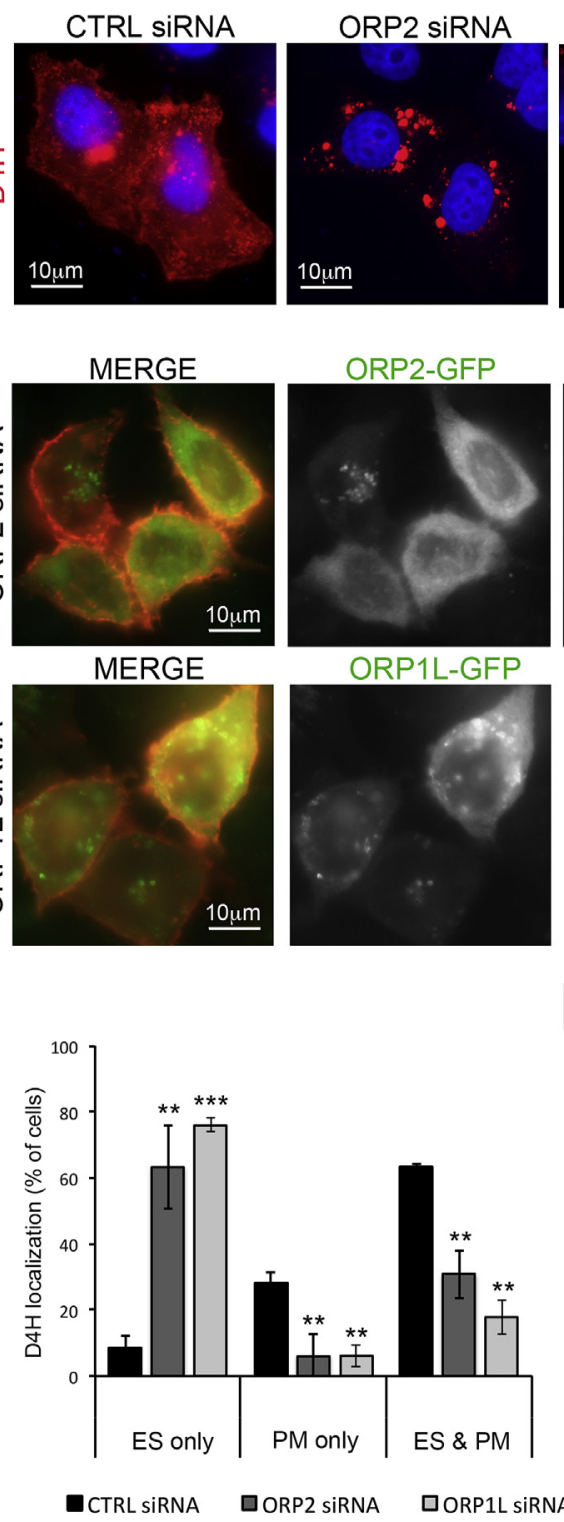

ORP1L-GFP

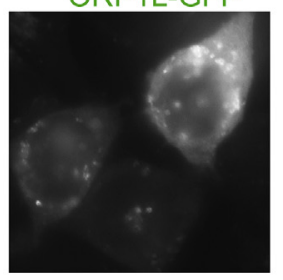

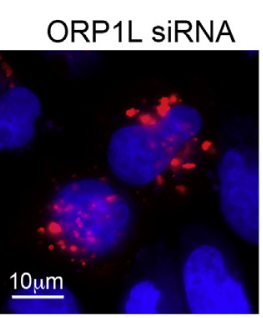

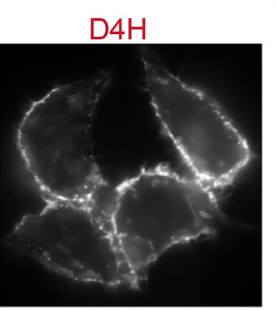

$\mathrm{D} 4 \mathrm{H}$
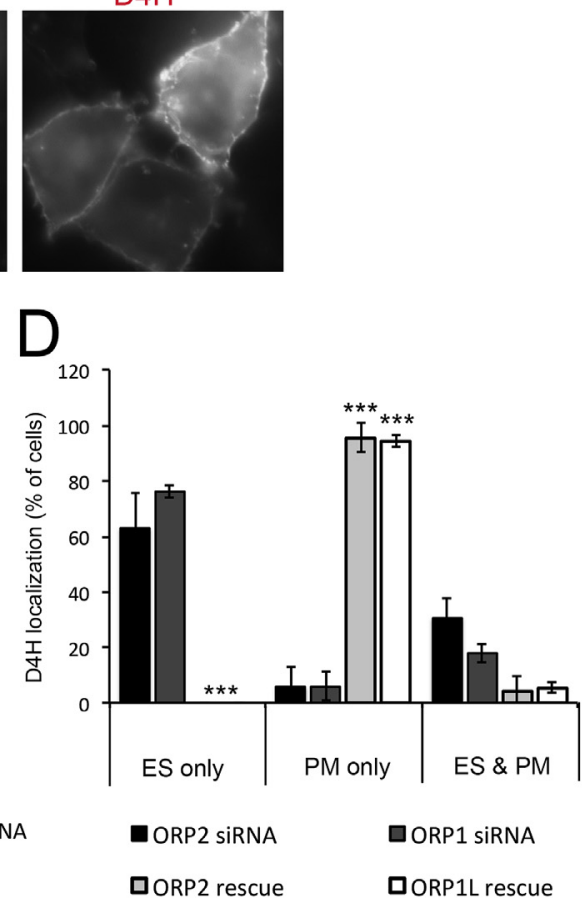

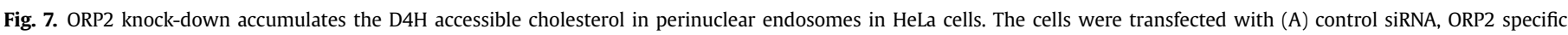

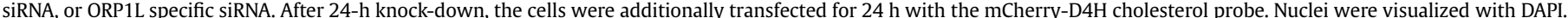

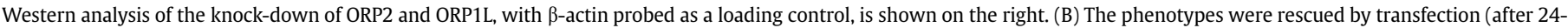

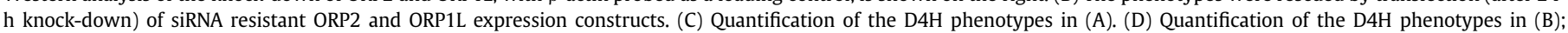

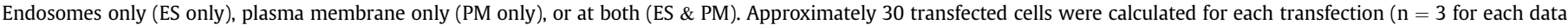
point); ${ }^{* *} \mathrm{p}<0.01,{ }^{* * *} \mathrm{p}<0.001$, comparison to the CTRL siRNA (C) or to the ORP2 and ORP1L siRNA treatments (D).

$\mathrm{H}^{178-179} \mathrm{~A}, \mathrm{~K}^{423} \mathrm{~A}$ (mHHK), with all three PIPs were attenuated, but the PIP binding was not abolished. This suggests that the observed signals may involve an unspecific aspect or partial binding at a site different from the ORD pocket. Therefore, the $K_{d}$ values determined must be considered with caution. The pull-down assay for binding of detergent-solubilized $\left[{ }^{3} \mathrm{H}\right]$ cholesterol to ORP2 verified the specific binding earlier suggested [19], but, possibly due to the necessity of solubilizing the cholesterol with detergent, a $\mathrm{K}_{\mathrm{d}}$ could not be determined for this interaction. It has previously been reported that the affinity of the prototype ORP, OSBP, for cholesterol is significantly lower than for oxysterol ligands such as $250 \mathrm{HC}$ [44-46]. We therefore find it likely that the affinity of ORP2 for cholesterol is lower than for its high-affinity oxysterol ligand, 22(R) OHC $\left(1.4 \times 10^{-8} \mathrm{M}\right.$; [19]). We have in previous studies and during the present investigation observed that purification of fully soluble recombinant ORP2 is challenging - detailed analysis of the folding status of ORP2 produced in E. coli in future work is therefore warranted.

We observed that the mutant ORP2 with attenuated PIP binding, ORP2(mHHK), displayed enhanced localization to LDs, similar to the sterol-binding pocket point mutant ORP2 I249W described in Refs. [19,27]. This suggests that PIP interactions play important roles in the targeting of ORP2 to non-LD locations, and that abolishing these interactions by mutating ORP2 results in a shift of ORP2 to its second subcellular location, the LDs [19].

By using the fluorescent cholesterol-binding probe mCherry$\mathrm{D} 4 \mathrm{H}$ [42], we show that overexpression of wild-type ORP2 reduces the D4H cholesterol signal in endosomes, while the PIP- 


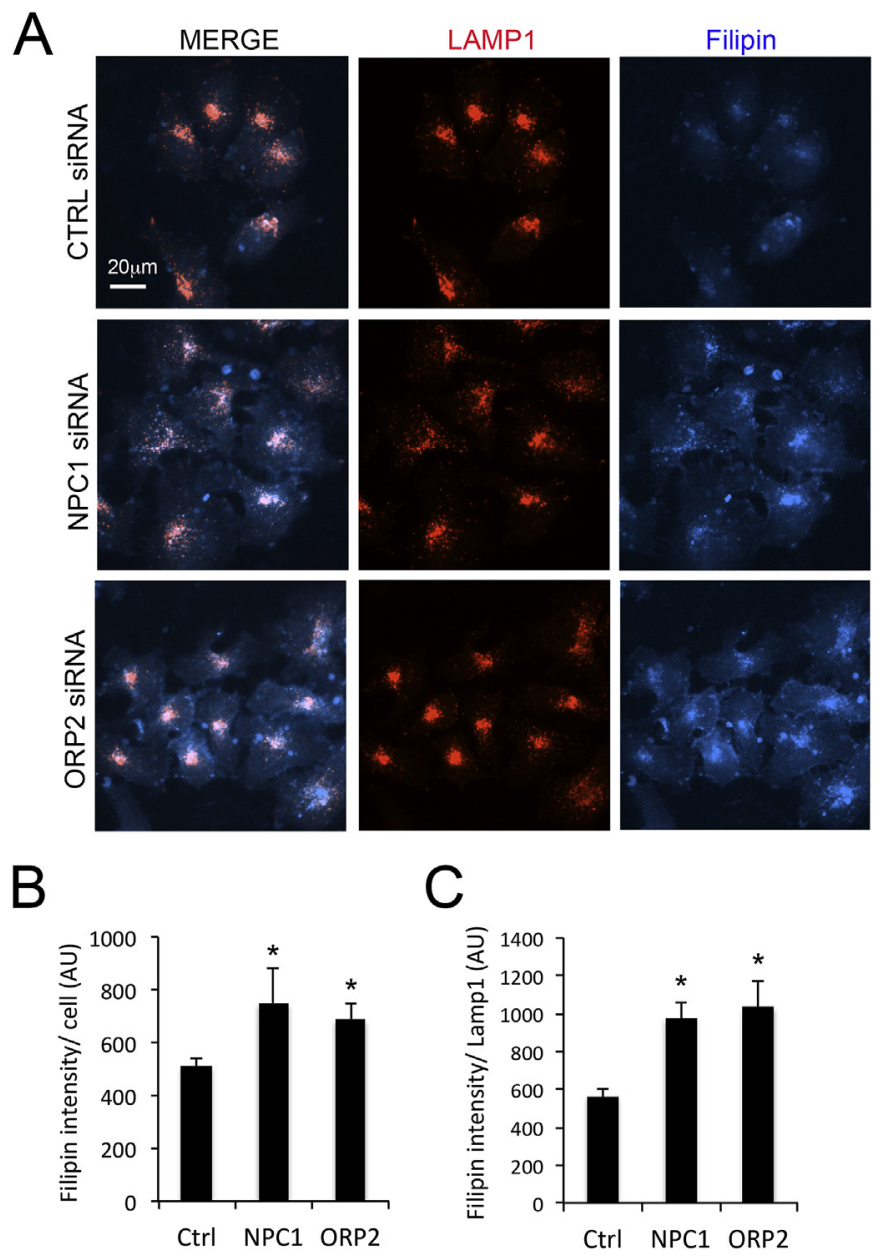

Fig. 8. Late endosomal/lysosomal cholesterol accumulation upon ORP2 knock-down as confirmed by filipin staining. (A) HeLa cells transfected for $48 \mathrm{~h}$ with control or ORP2specific siRNAs were stained with filipin and anti-LAMP1 antibodies. Knock-down of Niemann-Pick C1 (NPC1) was carried out as a positive control. (B) Quantification of the total cell filipin intensity $(\mathrm{C})$ and that in LAMP-1-positive compartments; $\mathrm{N}=50$ cells; ${ }^{*} \mathrm{p}<0.05$.

binding attenuated mutant ORP2(mHHK) has the opposite effect, shifting the D4H signal towards punctate/vesicular endosomal elements. This observation suggests that ORP2 has the capacity to promote the transfer of cholesterol from late endocytic compartments, consistent with its ability to enhance cellular cholesterol efflux to a variety of extracellular acceptors [24,25]. A key question was whether this is merely an overexpression artefact or whether it reflects a true function of the endogenous cellular ORP2. We therefore knocked down ORP2 to see if its depletion would cause a similar phenotype as the PIP-binding attenuated mutant. Indeed, similar to knock-down of ORP1L, which is suggested to mediate cholesterol transport between LEs and the ER [35,37,40], knockdown of ORP2 shifted the D4H and filipin towards LEs/lysosomes, suggesting that the endogenous function of ORP2 involves the egress of cholesterol from late endocytic compartments. This function appears to involve the recognition and possibly transfer of a PIP(s), since overexpression of the ORP2(mHHK) mutant resulted in the same phenotype as the knock-down. Interestingly, an earlier study implied that ORP2 plays, together with the closely related ORP1S, a role in mediating the transport of PM cholesterol to the ER and LD in A431 cells [26]. Thus, ORP2 may execute functions at two or several distinct cholesterol transport routes, considering that ORP1L is reported to play roles in both LE-ER and ER-LD transport of cholesterol $[35,37,40]$ and ORP5 and -8 to execute lipid transport or other functions at both ER-PM and ER-mitochondria contacts [6,47].

Concerning the reported endosomal cholesterol transport function of ORP1L, it is truly exciting that we identified ORP1L as a putative protein-protein interaction partner of ORP2 [21]. In the present study we produced more evidence for this interaction by co-immunoprecipitation of the two proteins and by BiFC, and demonstrated their partial co-localization at late endocytic compartments. This new observation is consistent with the data showing a similar shift in the distribution of the D4H cholesterol probe upon knock-down of ORP2 or ORP1L, indicating a functional relatedness or interplay between the two related proteins. In a DHE transfer assay, in which OSBP showed a significant sterol transfer activity, recombinant ORP2 preparations were devoid of activity, suggesting that ORP2 by itself may be unable to act as a sterol transporter. While OSBP induced efficient clustering of vesicles as judged from DLS experiments, ORP2 was unable to do this. These experiments should in future studies be expanded to different vesicle lipid and protein compositions. However, they indicate that, a 'short' ORP lacking a PH domain such as ORP2 may have a limited capacity of membrane tethering as compared to OSBP and other 'long' ORPs [6,10,38,48].

As a conclusion, the present study demonstrates that ORP2 binds several phosphoinositides, both $\mathrm{PI}(4) \mathrm{P}$ and multiply phosphorylated species. The data on transfected cells suggests that ORP2 has an important function in the removal of cholesterol from endosomes, which depends on membrane PIPs. Moreover, ORP2 interacts with the endosomal cholesterol transporter/sensor ORP1L. The present study paves way for more detailed investigations of ORP2 function.

\section{Authors' contributions}

A.Ko., A.A., K.T., H.K. and E.J. performed the experiments. A. Ki, P.S., J.P., T.V., V.M.O. and E.I. designed the experiments and interpreted the results together with A. Ko. V.M.O., A. Ko. and H.K. wrote the manuscript and all authors commented on the manuscript.

\section{Funding}

This study was supported by grants from the Academy of Finland (285223 to V.M.O.), the University of Helsinki Doctoral Programme in Biomedicine (H.K.), the Finnish Concordia Fund (H.K.), the Ida Montin Foundation (H.K), the Finnish-Norwegian Medical Foundation (H.K.), the Aarne Koskelo Foundation (H.K.), the Orion Research Foundation (H.K.), the Päivikki and Sakari Sohlberg Foundation (H.K.), the Sigrid Juselius Foundation, the Magnus Ehrnrooth Foundation, and the Finnish Foundation for Cardiovascular Research (V.M.O.). The funding bodies played no role in the study design, analysis or interpretation of the data, writing of the report or the decision to submit the article for publication.

\section{Conflicts of interest}

The authors declare no conflict of interest.

\section{Acknowledgments}

We thank Tarja Grundström and Riikka Kosonen for expert technical assistance, and Teemu Suutari for his expert advice and support with the SPR instrument. Prof. Gregory Fairn (Department of Biochemistry, University of Toronto, ON, Canada) is thanked for kindly providing the fluorescent $\mathrm{D} 4 \mathrm{H}$ construct and Prof. Bruno 


\section{Antonny, (Institut de Pharmacologie Moléculaire et Cellulaire, Valbonne, France) for the recombinant OSBP protein.}

\section{Appendix A. Supplementary data}

Supplementary data to this article can be found online at https://doi.org/10.1016/j.biochi.2018.12.013.

\section{References}

[1] G. Di Paolo, P. De Camilli, Phosphoinositides in cell regulation and membrane dynamics, Nature 443 (2006) 651-657.

[2] G. van Meer, D.R. Voelker, G.W. Feigenson, Membrane lipids: where they are and how they behave, Nat. Rev. Mol. Cell Biol. 9 (2008) 112-124.

[3] A.M. Anniss, J. Apostolopoulos, S. Dworkin, L.E. Purton, R.L. Sparrow, An oxysterol-binding protein family identified in the mouse, DNA Cell Biol. 21 (2002) 571-580.

[4] C.J. Jaworski, E. Moreira, A. Li, R. Lee, I.R. Rodriguez, A family of 12 human genes containing oxysterol-binding domains, Genomics 78 (2001) 185-196.

[5] M. Lehto, S. Laitinen, G. Chinetti, M. Johansson, C. Ehnholm, B. Staels, E. Ikonen, V.M. Olkkonen, The OSBP-related protein family in humans, J. Lipid Res. 42 (2001) 1203-1213.

[6] J. Chung, F. Torta, K. Masai, L. Lucast, H. Czapla, L.B. Tanner, P. Narayanaswamy, M.R. Wenk, F. Nakatsu, P. De Camilli, INTRACELLULAR TRANSPORT. PI4P phosphatidylserine countertransport at ORP5- and ORP8-mediated ER-plasma membrane contacts, Science 349 (2015) 428-432.

[7] M. de Saint-Jean, V. Delfosse, D. Douguet, G. Chicanne, B. Payrastre, W. Bourguet, B. Antonny, G. Drin, Osh4p exchanges sterols for phosphatidylinositol 4-phosphate between lipid bilayers, J. Cell Biol. 195 (2011) 965-978.

[8] Y.J. Im, S. Raychaudhuri, W.A. Prinz, J.H. Hurley, Structural mechanism for sterol sensing and transport by OSBP-related proteins, Nature 437 (2005) $154-158$.

[9] K. Maeda, K. Anand, A. Chiapparino, A. Kumar, M. Poletto, M. Kaksonen, A.C. Gavin, Interactome map uncovers phosphatidylserine transport by oxysterol-binding proteins, Nature 501 (2013) 257-261.

[10] B. Mesmin, J. Bigay, J. Moser von Filseck, S. Lacas-Gervais, G. Drin, B. Antonny, A four-step cycle driven by PI(4)P hydrolysis directs sterol/PI(4)P exchange by the ER-Golgi tether OSBP, Cell 155 (2013) 830-843.

[11] J. Moser von Filseck, A. Copic, V. Delfosse, S. Vanni, C.L. Jackson, W. Bourguet, G. Drin, INTRACELLULAR TRANSPORT. Phosphatidylserine transport by ORP/ Osh proteins is driven by phosphatidylinositol 4-phosphate, Science 349 (2015) 432-436.

[12] J. Tong, H. Yang, S.H. Eom, Y.J. Im, Structure of osh3 reveals a conserved mode of phosphoinositide binding in oxysterol-binding proteins, Structure 21 (2013) 1203-1213.

[13] C.J. Loewen, A. Roy, T.P. Levine, A conserved ER targeting motif in three families of lipid binding proteins and in Opi1p binds VAP, EMBO J. 22 (2003) 2025-2035.

[14] V.M. Olkkonen, S. Li, Oxysterol-binding proteins: sterol and phosphoinositide sensors coordinating transport, signaling and metabolism, Prog. Lipid Res. 52 (2013) 529-538.

[15] H. Kentala, M. Weber-Boyvat, V.M. Olkkonen, OSBP-related protein family: mediators of lipid transport and signaling at membrane contact sites, Int. Rev. Cell Mol. Biol. 321 (2016) 299-340.

[16] S.C. Helle, G. Kanfer, K. Kolar, A. Lang, A.H. Michel, B. Kornmann, Organization and function of membrane contact sites, Biochim. Biophys. Acta 1833 (2013) 2526-2541.

[17] M.J. Phillips, G.K. Voeltz, Structure and function of ER membrane contact sites with other organelles, Nat. Rev. Mol. Cell Biol. 17 (2016) 69-82.

[18] B. Mesmin, J. Bigay, J. Polidori, D. Jamecna, S. Lacas-Gervais, B. Antonny, Sterol transfer, PI4P consumption, and control of membrane lipid order by endogenous OSBP, EMBO J. 36 (2017) 3156-3174.

[19] R. Hynynen, M. Suchanek, J. Spandl, N. Back, C. Thiele, V.M. Olkkonen, OSBPrelated protein 2 is a sterol receptor on lipid droplets that regulates the metabolism of neutral lipids, J. Lipid Res. 50 (2009) 1305-1315.

[20] H. Kentala, S.G. Pfisterer, V.M. Olkkonen, M. Weber-Boyvat, Sterol liganding of OSBP-related proteins (ORPs) regulates the subcellular distribution of ORPVAPA complexes and their impacts on organelle structure, Steroids 99 (2015) 248-258.

[21] H. Kentala, A. Koponen, A.M. Kivelä, R. Andrews, C. Li, Y. Zhou, V.M. Olkkonen, Analysis of ORP2-knockout hepatocytes uncovers a novel function in actin cytoskeletal regulation, Faseb. J. 32 (2018) 1281-1295.

[22] H. Kentala, A. Koponen, H. Vihinen, J. Pirhonen, G. Liebisch, Z. Pataj, A. Kivelä, S. Li, L. Karhinen, E. Jääskeläinen, R. Andrews, L. Meriläinen, S. Matysik, E. Ikonen, Y. Zhou, E. Jokitalo, V.M. Olkkonen, OSBP-related protein-2 (ORP2): a novel Akt effector that controls cellular energy metabolism, Cell. Mol. Life Sci. 75 (2018) 4041-4057.

[23] T. Escajadillo, H. Wang, L. Li, D. Li, M.B. Sewer, Oxysterol-related-bindingprotein related Protein-2 (ORP2) regulates cortisol biosynthesis and cholesterol homeostasis, Mol. Cell. Endocrinol. 427 (2016) 73-85.

[24] R. Hynynen, S. Laitinen, R. Käkelä, K. Tanhuanpää, S. Lusa, C. Ehnholm,
P. Somerharju, E. Ikonen, V.M. Olkkonen, Overexpression of OSBP-related protein 2 (ORP2) induces changes in cellular cholesterol metabolism and enhances endocytosis, Biochem. J. 390 (2005) 273-283.

[25] S. Laitinen, M. Lehto, S. Lehtonen, K. Hyvärinen, S. Heino, E. Lehtonen, C. Ehnholm, E. Ikonen, V.M. Olkkonen, ORP2, a homolog of oxysterol binding protein, regulates cellular cholesterol metabolism, J. Lipid Res. 43 (2002) $245-255$.

[26] M. Jansen, Y. Ohsaki, L. Rita Rega, R. Bittman, V.M. Olkkonen, E. Ikonen, Role of ORPs in sterol transport from plasma membrane to ER and lipid droplets in mammalian cells, Traffic 12 (2011) 218-231.

[27] M. Suchanek, R. Hynynen, G. Wohlfahrt, M. Lehto, M. Johansson, H. Saarinen, A. Radzikowska, C. Thiele, V.M. Olkkonen, The mammalian OSBP-related proteins (ORP) bind 25-hydroxycholesterol in an evolutionarily conserved pocket, Biochem. J. 405 (2007) 473-480.

[28] Y. Xu, Y. Liu, N.D. Ridgway, C.R. McMaster, Novel members of the human oxysterol-binding protein family bind phospholipids and regulate vesicle transport, J. Biol. Chem. 276 (2001) 18407-18414.

[29] M. Weber-Boyvat, H. Kentala, J. Peränen, V.M. Olkkonen, Ligand-dependent localization and function of ORP-VAP complexes at membrane contact sites, Cell. Mol. Life Sci. 72 (2015) 1967-1987.

[30] J. Peränen, M. Rikkonen, M. Hyvönen, L. Kääriäinen, T7 vectors with modified T7lac promoter for expression of proteins in Escherichia coli, Anal. Biochem. 236 (1996) 371-373.

[31] M. Johansson, M. Lehto, K. Tanhuanpää, T.L. Cover, V.M. Olkkonen, The oxysterol-binding protein homologue ORP1L interacts with Rab7 and alters functional properties of late endocytic compartments, Mol. Biol. Cell 16 (2005) 5480-5492.

[32] M. Weber-Boyvat, S. Li, K.P. Skarp, V.M. Olkkonen, D. Yan, J. Jäntti, Bimolecular fluorescence complementation (BiFC) technique in yeast Saccharomyces cerevisiae and mammalian cells, Methods Mol. Biol. 1270 (2015) 277-288.

[33] M. Ngo, N.D. Ridgway, Oxysterol binding protein-related Protein 9 (ORP9) is a cholesterol transfer protein that regulates Golgi structure and function, Mol. Biol. Cell 20 (2009) 1388-1399.

[34] R. Ghai, X. Du, H. Wang, J. Dong, C. Ferguson, A.J. Brown, R.G. Parton, J.W. Wu, H. Yang, ORP5 and ORP8 bind phosphatidylinositol-4, 5-biphosphate (PtdIns $\left.(4,5) \mathrm{P}_{2}\right)$ and regulate its level at the plasma membrane, Nat. Commun. 8 (2017) 757.

[35] E.R. Eden, E. Sanchez-Heras, A. Tsapara, A. Sobota, T.P. Levine, C.E. Futter, Annexin A1 tethers membrane contact sites that mediate ER to endosome cholesterol transport, Dev. Cell 37 (2016) 473-483.

[36] M. Johansson, N. Rocha, W. Zwart, I. Jordens, L. Janssen, C. Kuijl, V.M. Olkkonen, J. Neefjes, Activation of endosomal dynein motors by stepwise assembly of Rab7-RILP-p150Glued, ORP1L, and the receptor betalll spectrin, J. Cell Biol. 176 (2007) 459-471.

[37] H. Kobuna, T. Inoue, M. Shibata, K. Gengyo-Ando, A. Yamamoto, S. Mitani, H. Arai, Multivesicular body formation requires OSBP-related proteins and cholesterol, PLoS Genet. 6 (2010), https://doi.org/10.1371/journal.pgen.1001055 pii: e1001055.

[38] N. Rocha, C. Kuijl, R. van der Kant, L. Janssen, D. Houben, H. Janssen, W. Zwart, J. Neefjes, Cholesterol sensor ORP1L contacts the ER protein VAP to control Rab7-RILP-p150 Glued and late endosome positioning, J. Cell Biol. 185 (2009) 1209-1225.

[39] R. van der Kant, A. Fish, L. Janssen, H. Janssen, S. Krom, N. Ho, T. Brummelkamp, J. Carette, N. Rocha, J. Neefjes, Late endosomal transport and tethering are coupled processes controlled by RILP and the cholesterol sensor ORP1L, J. Cell Sci. 126 (2013) 3462-3474.

[40] K. Zhao, N.D. Ridgway, Oxysterol-binding protein-related protein 1L regulates cholesterol egress from the endo-lysosomal system, Cell Rep. 19 (2017) 1807-1818.

[41] T.K. Kerppola, Bimolecular fluorescence complementation (BiFC) analysis as a probe of protein interactions in living cells, Annu. Rev. Biophys. 37 (2008) 465-487.

[42] M. Maekawa, G.D. Fairn, Complementary probes reveal that phosphatidylserine is required for the proper transbilayer distribution of cholesterol, J. Cell Sci. 128 (2015) 1422-1433.

[43] M.T. Vanier, Complex lipid trafficking in Niemann-Pick disease type C, J. Inherit. Metab. Dis. 38 (2015) 187-199.

[44] F.R. Taylor, S.E. Saucier, E.P. Shown, E.J. Parish, A.A. Kandutsch, Correlation between oxysterol binding to a cytosolic binding protein and potency in the repression of hydroxymethylglutaryl coenzyme A reductase, J. Biol. Chem. 259 (1984) 12382-12387.

[45] P.Y. Wang, J. Weng, R.G. Anderson, OSBP is a cholesterol-regulated scaffolding protein in control of ERK 1/2 activation, Science 307 (2005) 1472-1476.

[46] P.Y. Wang, J. Weng, S. Lee, R.G. Anderson, N-terminus controls sterol binding while c-terminus regulates scaffolding function of OSBP, J. Biol. Chem. 283 (2008) 8034-8045.

[47] R. Galmes, A. Houcine, A.R. van Vliet, P. Agostinis, C.L. Jackson, F. Giordano, ORP5/ORP8 localize to endoplasmic reticulum-mitochondria contacts and are involved in mitochondrial function, EMBO Rep. 17 (2016) 800-810.

[48] M. Sohn, M. Korzeniowski, J.P. Zewe, R.C. Wills, G.R.V. Hammond, J. Humpolickova, L. Vrzal, D. Chalupska, V. Veverka, G.D. Fairn, E. Boura, T. Balla, PI(4,5) $\mathrm{P}_{2}$ controls plasma membrane PI4P and PS levels via ORP5/8 recruitment to ER-PM contact sites, J. Cell Biol. 217 (2018) 1797-1813. 